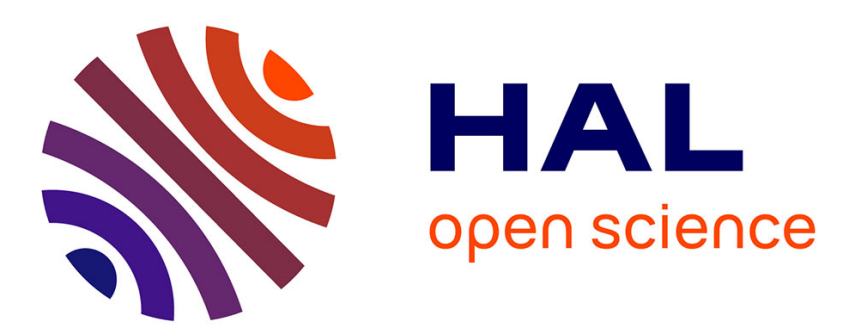

\title{
Hybrid approach for woven fabric modelling based on discrete hypoelastic behaviour and experimental validation
}

Mondher Nasri, Christian Garnier, Fethi Abbassi, Ahmad Rashed Labanieh, Olivier Dalverny, Ali Zghal

\section{To cite this version:}

Mondher Nasri, Christian Garnier, Fethi Abbassi, Ahmad Rashed Labanieh, Olivier Dalverny, et al.. Hybrid approach for woven fabric modelling based on discrete hypoelastic behaviour and experimental validation. Composite Structures, 2019, 209, pp.992-1004. 10.1016/j.compstruct.2018.10.081 . hal02359793

\section{HAL Id: hal-02359793 \\ https://hal.science/hal-02359793}

Submitted on 12 Nov 2019

HAL is a multi-disciplinary open access archive for the deposit and dissemination of scientific research documents, whether they are published or not. The documents may come from teaching and research institutions in France or abroad, or from public or private research centers.
L'archive ouverte pluridisciplinaire HAL, est destinée au dépôt et à la diffusion de documents scientifiques de niveau recherche, publiés ou non, émanant des établissements d'enseignement et de recherche français ou étrangers, des laboratoires publics ou privés. 


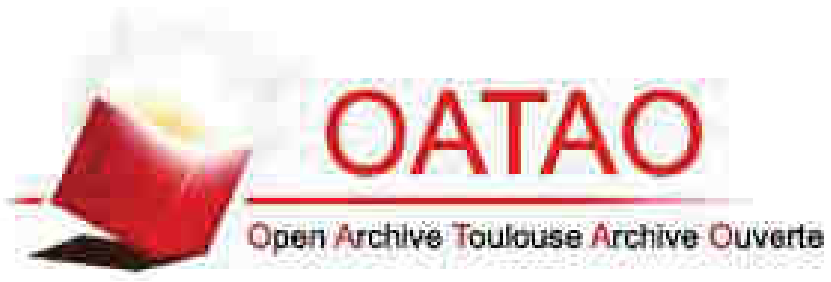

\section{Open Archive Toulouse Archive Ouverte (OATAO)}

OATAO is an open access repository that collects the work of some Toulouse researchers and makes it freely available over the web where possible.

This is an author's version published in: http://oatao.univ-toulouse.fr/22984

Official URL: https://doi.org/10.1016/j.compstruct.2018.10.081

\section{To cite this version:}

Nasri, Monder and Garnier, Christian and Abbassi, Fethi and Labanieh, Ahmad Rashed and Dalverny, Olivier and Zghal, Ali Hybrid approach for woven fabric modelling based on discrete hypoelastic behaviour and experimental validation. (2019) Composite Structures, 209. 992-1004. ISSN 0263-8223

Any correspondence concerning this service should be sent to the repository administrator: tech-oatao@listes-diff.inp-toulouse.fr 


\title{
Hybrid approach for woven fabric modelling based on discrete hypoelastic behaviour and experimental validation
}

\author{
M. Nasri ${ }^{\mathrm{a}, \mathrm{b}, *}$, C. Garnier ${ }^{\mathrm{a}, *}$, F. Abbassi ${ }^{\mathrm{c}}$, A.R. Labanieh $^{\mathrm{d}}$, O. Dalverny ${ }^{\mathrm{a}}$, A. Zghal ${ }^{\mathrm{b}}$ \\ ${ }^{a}$ University of Toulouse, INP-ENIT/LGP, 47 Avenue d'Azereix, 65016 Tarbes, France \\ ${ }^{\mathrm{b}}$ LMPE, ENSIT, University of Tunis, 5 Avenue Hussein, BP, 56, Bâb Manara, 1008, Tunisia \\ ${ }^{\mathrm{c}}$ College of Engineering and Technology, American University of the Middle East, Kuwait \\ ${ }^{\mathrm{d}}$ Laboratoire Génie et Matériaux Textiles (GEMTEX), ENSAIT, 95170 Roubaix, France
}

Keywords:

Hybrid discrete hypoelastic

Non-linearity

Finite element analysis

Bias extension test

Woven fabric

Composite forming

\begin{abstract}
A B S T R A C T
A non-linear discrete hybrid approach based on the association of hypoelastic continuous elements (non-linear shear behaviour) with specific connectors (non-linear tension stiffness) is developed. It allows the simulation of a two-dimensional (2D) woven reinforcement forming via an accurate explicit finite element analysis. This approach allows the simulation of $2 \mathrm{D}$ unbalanced fabrics uncoupling tensile and shear behaviour. It only needs a few parameters to be identified, and shows a good agreement with the experiments. The identification of the model parameters is investigated, and their relevance is analysed in reference tests. To determine the continuous element behaviour, a VUMAT hypoelastic model is implemented in Abaqus/Explicit. This model allows the prediction of fibre stresses and the accurate determination of shear angle in large deformations. Identification and validation of the model are performed using standard characterisation fabric tests. The experimental characterisation provided the numerical data to produce a representational prediction of the deformed fabric geometry and shear angle distribution. Further, the behaviour of the carbon woven reinforcement is identified. A bias extension test is used to both calibrate and validate the model. The capability of the model is illustrated to simulate deep drawing, and to compare with the experimental results of hemispherical forming.
\end{abstract}

\section{Introduction}

For several decades, composite materials have been increasingly used in many sectors, such as aeronautics where composites are already used on a large scale. The latest generation of airliners are made with more than $50 \%$ mass of composites [1]. Achieving a lightweight product and saving energy are the main challenges in the aircraft industry production, which explains the increase in composite demand and the diversity of its applications [2]. Several forming processes of woven composites are classified under different categories. The liquid composite moulding process involves forming of dry materials into shapes without resin (an example of such a process is the resin transfer moulding [3-5]). In this process, dry woven reinforcements are first formed, then the resin is injected to obtain the final shape [6,7]. This method has several disadvantages according to different points of view: difficulty of controlling the final shape and the effective mechanical properties, high cost of implementation, and low production rate. Some other problems are related to preform deformation draping: tension fibres between longitudinal and transverse direction, fibre disorientation, and wrinkling or local buckling [8]. Knowledge about the process and accurate modelling are essential for the analysis of composite structures in service [8]. Numerical approaches for modelling the forming of woven fabric composite reinforcement belong to two main categories that are related to the scale at which the analysis is made [9]. These approaches have several objectives with different impacts. First, it makes possible the determination of the feasibility, or the conditions of this possibility. Second, it allows predicting the position of fibres after forming $[8,10]$. The literature proposes several approaches for modelling the behaviour of woven fabrics. For example, draping of the woven reinforcements can be achieved either by geometric, continuous, discrete, or semi-discrete approaches. These geometric models involve placing a net on a surface along geodetic lines [11]. This approach is based on the work of Mark and Taylor [12] with certain simplifying assumptions (Inextensibility of yarns, no sliding at the intersections of warps and wefts, free spins between the warps and wefts and non-slip contact between woven reinforcement and draping tool) [13]. This method is simple and although temporally very interesting for predicting the orientation of the yarns, but does not take into

\footnotetext{
* Corresponding authors at: University of Toulouse, INP-ENIT/LGP, 47 Avenue d'Azereix, 65016 Tarbes, France.

E-mail addresses: mondher.nasri@enit.fr (M. Nasri), christian.garnier@enit.fr (C. Garnier).
} 


\begin{tabular}{|llll|}
\hline \multicolumn{2}{|l|}{ Nomenclature } & $E_{22}$ & Young's Modulus in weft direction \\
& & $G_{12}$ & In-plane shear rigidity \\
$\nabla$ & Vector gradient & $T_{1,2}$ & Transformation matrix \\
$\underline{\underline{\sigma}}$ & Cauchy stress tensor & $d \varepsilon_{F_{1,2}}$ & Strain increments \\
$\underline{\underline{\sigma}}^{\nabla}$ & Objective derivative of Cauchy stress tensor & $d \sigma_{1,2}$ & Stress increments \\
$\sigma_{N e w}$ & Updated stress tensor & $\gamma$ & Shear angle \\
$G N_{1,2}$ & Green-Naghdi basis & $\theta_{1,2}$ & Angle between warp or weft and Green-Naghdi basis \\
$G N_{1,2}^{0}$ & Initial Green-Naghdi basis & $F_{b}$ & Normal bias force \\
$F_{1,2}^{0}$ & Initial material basis & $F_{s h}(\gamma)$ & Normalised shear force \\
$F_{1,2}$ & Material basis & $F_{c}$ & Connector force \\
$\underline{\underline{F}}$ & Deformation gradient tensor & $U_{c}$ & Connector displacement \\
$\underline{\underline{R}}$ & Rotation tensor & $e$ & Thickness \\
$\underline{\underline{U}}$ & Right stretch tensor & $K(u)$ & Connector stiffness \\
$\underline{\underline{D}}$ & Constitutive tensor & $N$ & Number of connectors in direction Y \\
$\underline{\underline{D}}$ & Strain rate tensor & $n$ & Number of connectors in direction X \\
$E_{11}$ & Young's Modulus in warp direction & $n$ & \\
\hline
\end{tabular}

account the physical properties of yarns in the warp and weft directions. Thus, the result obtained is independent of the material used. This method is suitable for draping, but not for drawing processes, where a poor match with the experimental results had been observed [14]. This model also decouples the tension and shear behaviours [10]. The continuous approach considers the woven fabric as a macroscopically contained material, because it takes into account the homogenised overall behaviour of the reinforcement. The geometry of the reinforcement is illustrated by a finite element mesh of shell or membrane [15]. Three continuous approaches are described using a membrane and shell assumption.

(i) The first one is based on a continuous non-orthogonal elastic law. This approach involves formulating the constitutive law by linking the stress and strain through a continuous medium in a non-orthogonal basis described in the directions of the reinforcing yarns because of the small influence of the shear angle on the biaxial behaviour [16]. Pu Xue et al. developed a model that indicates the behaviour of the woven composite using a non-orthogonal coordinate system [17].

(ii) The second approach is the continuous hypoelastic one. In this case, the stress increments are directly related to the strain increments with a constitutive tensor containing the material stiffness moduli [18]. The main advantage is the representation of the nonlinear behaviour and it is often implemented in finite element analyses at large strains. Several studies developed the hypoelastic laws for fabric reinforcement simulation [19-21] and for woven structures [22].

(iii) The third approach is the hyperelastic continuous model, which is also based on the decoupling between tension and shear. It relies on the definition of an energy potential from which the hyperelastic constitutive model is derived and which reproduces the non-linear mechanical behaviour of fibrous reinforcements [9,23]. This potential is defined as the sum of three terms: the deformation energies in the two yarn directions and the shear behaviour. Aimene et al. [24] proposed a model of anisotropic hyperelastic behaviour for the simulation of woven fibrous reinforcements, which is likely to reproduce the non-linear behaviour observed on these woven reinforcements. The work presented by Erchiqui et al. [25] demonstrates that this approach is able to predict the influence of fibre orientation in the thermoforming process.

Furthermore, numerical modelling using the discrete approach represents the reinforcement as an elementary physical cell, which uses finite elements of bars, beams, membranes, or shells $[26,27]$. The advantage of this approach is that it can justify certain global behaviour of tissues from its internal structure. In several publications, it is shown that the advantage of this reinforcement method to simulate forming problems [28-30]. Boubaker et al. [31] proposed a model of woven reinforcements based on a mass-spring system. In [32], Sharma et al. proposed a model based on an elementary cell constructed only with elastic bars on the sides and an elastoplastic bar positioned according to one of the diagonals to model the non-linear shear behaviour. In 2010, the discrete modelling is still applied by Sherwood et al. [33], who used this approach to model two types of fabrics (glass taffeta and $2 \times 2$ twill). The discrete approach was also used by Najjar [34] to simulate the stamping process of an interlock reinforcement type G1151. The tension stiffness was modelled by connectors and the shear behaviour was modelled as elastic. In 2011, Harrison [35] proposed a behaviour model by combining a non-orthogonal approach to manage shear in a shell element, and bars to describe the behaviour of yarns in tension.

The semi-discrete approach is a combination of the continuous and discrete approach. It is a mesoscopic approach of an elementary reinforcement cell using the finite element method. This approach is based on the virtual work theorem, which links internal, external, and acceleration works in the virtual displacement field [36].

In this present work, a hybrid discrete hypoelastic model is developed, and then compared with experimental results. To determine the behaviour of HexForce 48600 C 1300 carbon fabric during the preforming process, some basic mechanical tests should be conducted. Tensile testing campaigns, up to the warp and weft directions of 48600 C 1300 carbon fabric, were carried out to determine the rigidity of the fabric, which is itself introduced in the numerical simulation. The following aspects are presented in this paper:

- Material characterisation and determination of the model parameters,

- Formulation description of the hypoelastic and hybrid model,

- Identification of non-linear stiffness and shear,

- Validation of the shear and stress response on a single mesh and the bias extension simulation by comparing with marker tracking method data,

- Simulation of a hemispherical forming test,

- Comparison between the hemispherical forming test and numerical results.

\section{Materials and experimental investigations}

\subsection{Specimen and material used}

To determine the behaviour of woven carbon reinforcements, tensile and bias extension tests were carried out following three directions $\left(0^{\circ}, 45^{\circ}\right.$, and $\left.90^{\circ}\right)$, using $270 \mathrm{~mm} \times 50 \mathrm{~mm}$ samples with a $150 \mathrm{~mm}$ gauge length. In this work, the carbon fabric used is HexForce $48600 \mathrm{C}$ 
1300. This fabric is a $2 \times 2$ twill weave with a $0.62 \mathrm{~mm}$ thickness ply. Referring to the datasheet provided by Hexcel [37], this fabric is considered to be balanced (a fabric made up of equal numbers and sizes of warp and weft yarns). The fabric specifications and geometric properties are presented in Table 1.

\subsection{Tensile test}

Tensile tests along the warp and weft directions are conducted to characterise the stiffness of fabrics. In this experiment, the samples are loaded at a constant displacement rate of $2 \mathrm{~mm} / \mathrm{min}$ [38] on an Instron 550R testing machine. The load is recorded by the machine and the displacement is recorded by a digital image correlation (DIC) system (Fig. 1). To avoid slipping between the specimen and the jaws and to ensure a smooth surface sheet, steel plates are used for clamping $(60 \times 50 \mathrm{~mm})$.

The load cell is rated at $100 \mathrm{kN}$, and the controlled room temperature is $22^{\circ} \mathrm{C}$. The specimen is placed without any pre-loading; as reference for the test, the displacement and load are set as zero. Furthermore, the shear stiffness of the fabric is increased significantly by yarn pretension. The effective stiffness of the fabric is determined from the slope of the load-displacement curve.

\subsection{Plane shearing and experimental analysis}

\subsubsection{Bias extension test of woven fabric $48600 \mathrm{C} 1300$}

The yarns of the specimen are located at $\pm 45^{\circ}$ to the tensile direction, and the initial angle between the warp and weft is $90^{\circ}$. Bias extension tests are used to characterise the shear mechanisms of fabric reinforcement considering the low values of forces involved during this test. Testing of the specimens was conducted on an Instron 550R tensile machine, using a $500 \mathrm{~N}$ load cell under a $10 \mathrm{~mm} / \mathrm{min}$ displacement speed $[39,40]$. Moreover, the load-displacement diagrams are recorded. These tests are carried out at room temperature $\left(22^{\circ} \mathrm{C}\right)$. The ratio $\lambda$ between the length and width of the specimen should not be smaller than two $(\lambda=\mathrm{L} / \mathrm{W})$ in the bias extension tests [36], where $\mathrm{L}$ is the total length of the material, and $\mathrm{W}$ is the width of the specimen. This ratio should be greater than two in order to obtain pure shear in the centre of the specimen. Fig. 2 shows an idealised bias extension test sample with $\lambda=3$, in which the material is divided into three regions. This has been shown in [41], where the material is divided into three different regions (A, B, and C). The deformation in area B is located in the centre of the specimen and it can be considered as a pure shear area. The shear angle in area $\mathrm{C}$ is always half the shear angle in area B, while area $\mathrm{A}$ remains undeformed, assuming that yarns are inextensible and that no slip occurs in the specimen. During the bias extension tests, the angle $\alpha_{0}$ between the warp and weft gradually decreases. The shear angle $\gamma$ is calculated from the geometry of the bias extension test.

$\cos \left(\frac{\alpha}{2}\right)=\frac{(H+d)-W}{2(H-W) \cos \left(\frac{\alpha_{0}}{2}\right)}=\cos \left(\frac{\alpha_{0}}{2}\right)+\frac{d}{2(H-W) \cos \left(\left(\frac{\alpha_{0}}{2}\right)\right.}$

$\gamma=90^{\circ}-\alpha=90^{\circ}-2 \operatorname{arcos}\left(\frac{D+d}{\sqrt{2} D}\right)$

where $\mathrm{D}$ is the initial diagonal length of area $\mathrm{C}$, and $\mathrm{d}$ is the displacement of the mobile clamps of the tensile machine. Five samples were tested and the average response was computed. It is observed that the load recorded is very small ( $5.5 \mathrm{~N}$ maximum), whereas the displacement is very large (up to $50 \mathrm{~mm}$ at maximum load). The load increases to a maximum value of $5.5 \mathrm{~N}$ and then decreases progressively.

\subsubsection{Mark tracking method application}

The fundamental principle of the mark tracking method is to mark previously dried reinforcements with painted points at strategic locations, as illustrated in Fig. 3. This procedure allows the determination of the position of each mark for every configuration and the calculation of the displacements of these points between the initial and deformed configurations. The objective of such an approach is to monitor the behaviour of the yarns by tracking the marks in real time. Two CCD cameras are positioned to measure and systematically register two or more configurations: the initial, intermediate, and final one. In fact, the calculation of the three-dimensional (3D) marker positions is performed based on a standard network of markers, whose positions on the left camera $\left(x_{g}, y_{g}, z_{g}\right)$ are known in reference to the right camera $\left(X_{d}, Y_{d}, Z_{d}\right)$. The measurement of positions during loading is performed by a stereo-image correlation system. The DIC system used is the GOM ATOS system with the Aramis software. The numerical image acquisition is $1392 \times 1040$ pixels and the spatial resolution is less than $15 \mu \mathrm{m}$. Images are recorded during the test and analysed by the Aramis software to determine the full field displacements of markers [42]. The focal length of objects used is $35 \mathrm{~mm}$ for the tests at $0^{\circ} / 90^{\circ}$ and $12 \mathrm{~mm}$ for the tests at $45^{\circ}$ to increase the size of the observed area. The rigidity in shear is less than the tensile one; thus, the displacement in shear is much larger than the tensile one.

The angles between the marks are calculated using the variation law of cosines $\alpha \measuredangle$ (AB, BC). Thus, the shear angle at zone $\mathrm{B}$ is calculated as the average of the difference in global angle. For a quantitative comparison, the shear angle in zone B is averaged and plotted versus crosshead displacement. The ideal kinematic angle is also plotted.

In the evaluation, the mark tracking method for the different measurements is performed in the three areas of the specimen.

\subsection{Experimental results analysis}

\subsubsection{Tensile tests}

The resulting load-displacement curves for the woven fabric are shown in Fig. 4. Each curves are the average curves of 5 tests. They are composed of three distinct parts. The first one is non-linear until a $2 \mathrm{~mm}$ displacement. This stage corresponds to the setting up of the woven fabric, reducing the crimp phenomenon in this direction until the yarn is in tension. As the yarn strain begins, the stiffness becomes non-linear and increases until a linear trend is attained. The second part corresponds to the linear stage, where the tension of the fabric increases up to the maximum load. The last part is the progressive deterioration of the specimen until full unweaving of the fabric. The load-displacement behaviour of the fabric will be fitted with a 4th order polynomial allowing a non-linear stiffness description of the tensile test as will be explained in Section 3.

It can be seen that the stiffness in both directions is not exactly the same, which means that the fabric is not perfectly balanced.

To identify the rigidity of the yarns, a polynomial equation is used to fit the experimental force-displacement curve. The method consists of establishing the experimental trend curve and identifying the coefficients of the polynomial. The expression of total polynomial behaviour of order 4 is thus written as

$F_{t}=a_{4} u_{t}^{4}+a_{3} u_{t}^{3}+a_{2} u_{t}^{2}+a_{1} u_{t}+a_{0}$

Table 1

Specifications and geometric properties of 48600 C 1300 material.

\begin{tabular}{ll}
\hline Designation & $48600 \mathrm{C} 1300$ \\
\hline Type of yarn warp & T700SC 12K 50C \\
Type of yarn weft & T700SC 12K 50C \\
Mass per unit length of wire & $800 \mathrm{Tex}(\mathrm{g} / \mathrm{km})$ \\
Warp nominal construction & $3.7 \mathrm{yarn} / \mathrm{cm}$ \\
Weft nominal construction & $3.7 \mathrm{yarn} / \mathrm{cm}$ \\
Nominal weight & $600 \mathrm{~g} / \mathrm{m}^{2}$ \\
Surface density of fabric & $1.8 \mathrm{~g} / \mathrm{cm}^{3}$ \\
\hline
\end{tabular}




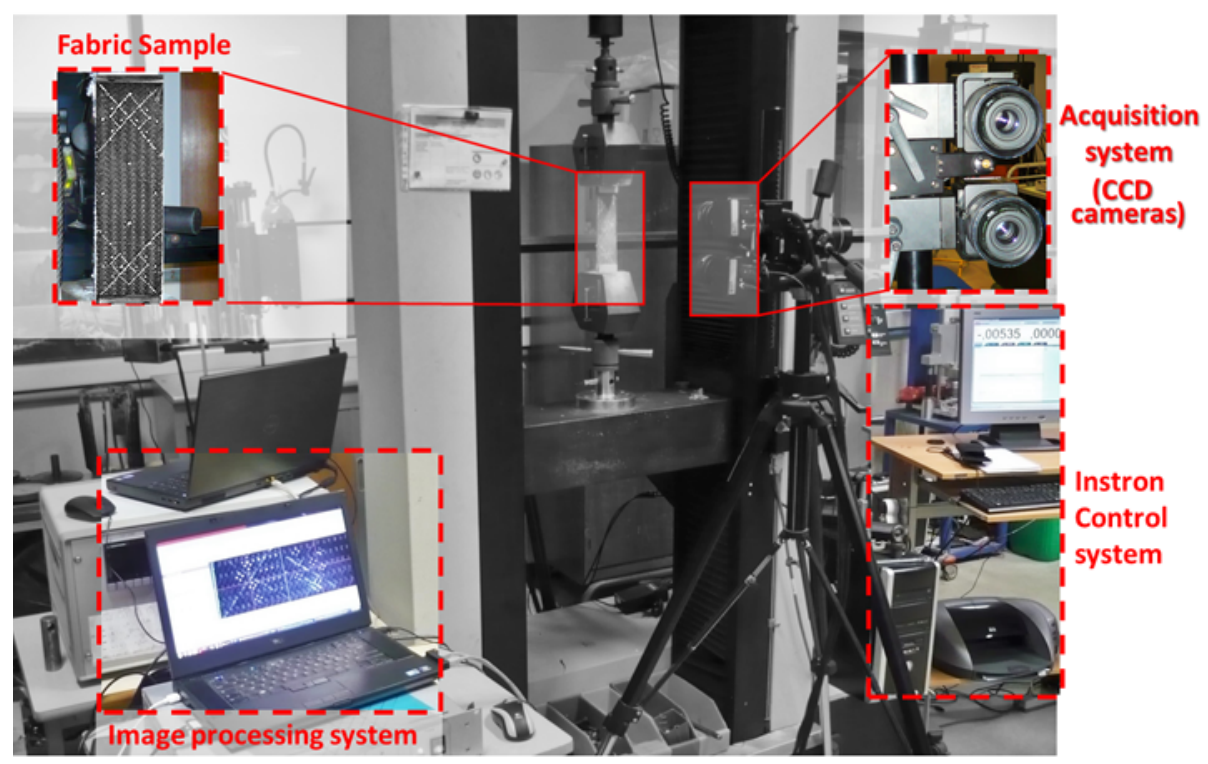

Fig. 1. Experimental setup for uniaxial tension and bias extension tests.

The method of accounting for this non-linear behaviour involves defining a displacement interval. The polynomial coefficients in a validity interval $[0 \mathrm{~mm}, 3.9 \mathrm{~mm}]$ was determined from the experimental trend curve. The total behaviour of the specimen is written in the following form:

$F_{t}=-170.85 \cdot u_{t}^{4}+573 \cdot u_{t}^{3}-123.13 \cdot u_{t}^{2}+19.75 \cdot u_{t}-3.446$

\subsubsection{Bias extension test}

The resulting load-displacement curves for the bias extension test are shown in Fig. 5.

The experimental shear angle is then calculated and compared to the kinematic angle (Fig. 6), which was explained in the previous section. Experimental and kinematic shear angles correlate well up to $21^{\circ}$ and then, the kinematic method overestimates the load observed from the test. The large clamp displacement and smaller shear angles, as shown by the experimental data, could be due to the appearance of yarn sliding. Actually, this phenomenon is commonly observed during bias extension testing $[43,44]$. The occurrence of sliding at the interface between the zones makes it possible to stop the increase of shear in the central zone [20].

To validate the theory of three shear areas, the mark tracking method is used to calculate the shear angles in zones A, B, and C, as shown Fig. 2. The calculation is done in the lower and upper part of the sample to sure that the deformation is symmetric. For a displacement value from $0 \mathrm{~mm}$ to $15 \mathrm{~mm}$, both shear angles in the lower and upper part and for each area A, B and C are equivalent. It also can be noted that the shear angles in area A (supposed to be unsheared) is not equal to $0^{\circ}$. Furthermore, for a displacement of $15 \mathrm{~mm}$, the average shear angle in zone B, supposed to be in pure shear, is equal to $20^{\circ}$, whereas in zone $\mathrm{C}$, supposed to be half sheared, the average shear angle is approximately $8^{\circ}$. The verification of the domain of validity of the kinematic hypothesis, in which the shear angle in the half-sheared zone $\mathrm{C}$ is half the value of the one in the central zone (pure shear), is followed. However, the two zones A near the tabs, supposed to be unsheared, show a slight shearing (Fig. 7).

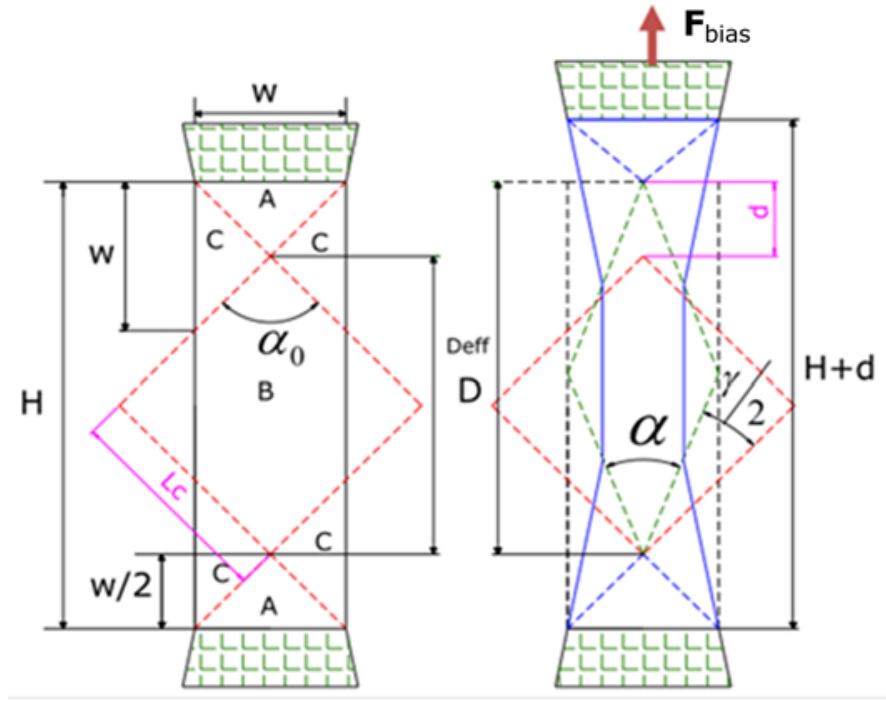

a)

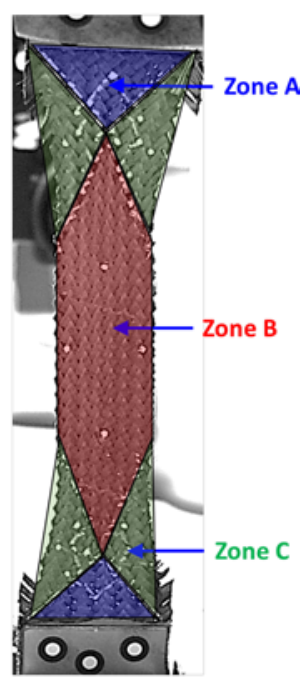

b)

Fig. 2. a) Scheme of bias extension test and b) experimental specimen. 


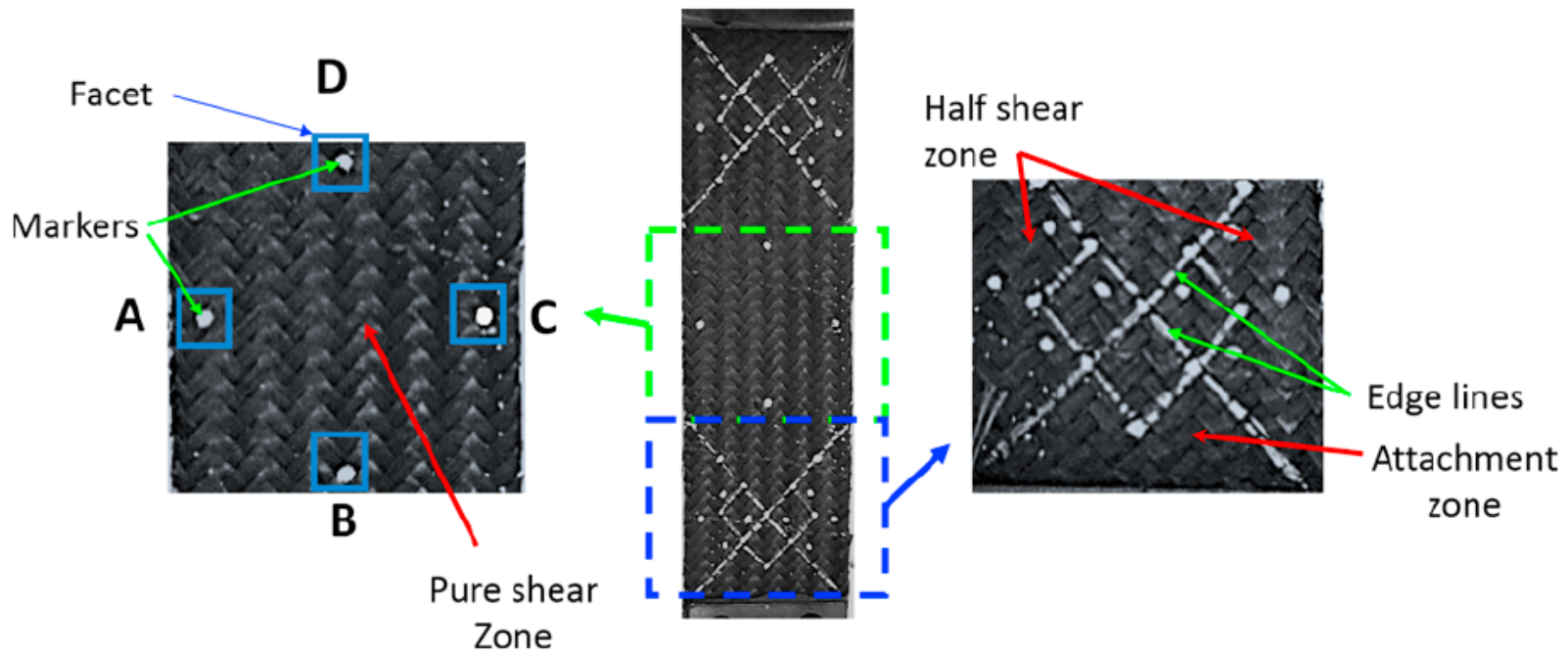

Fig. 3. Marking of woven 48600 C 1300.

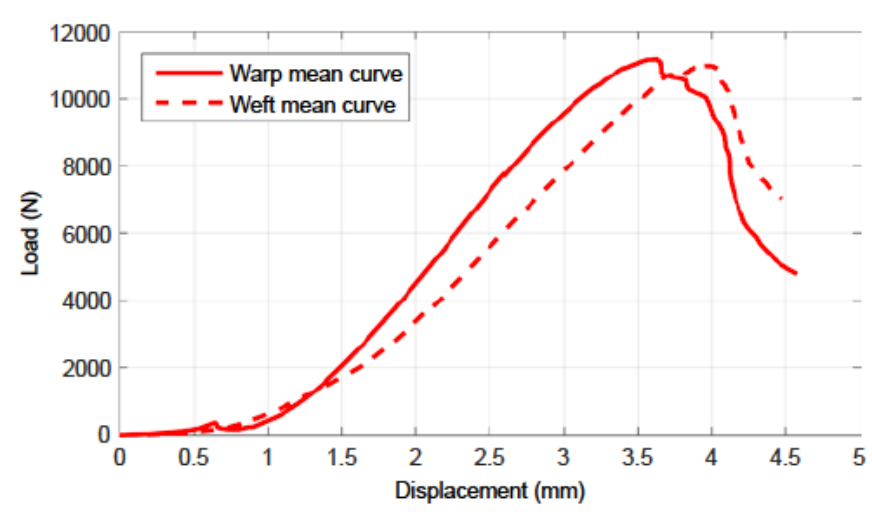

Fig. 4. Results of tensile test of 48600 C 1300 in warp and weft directions.

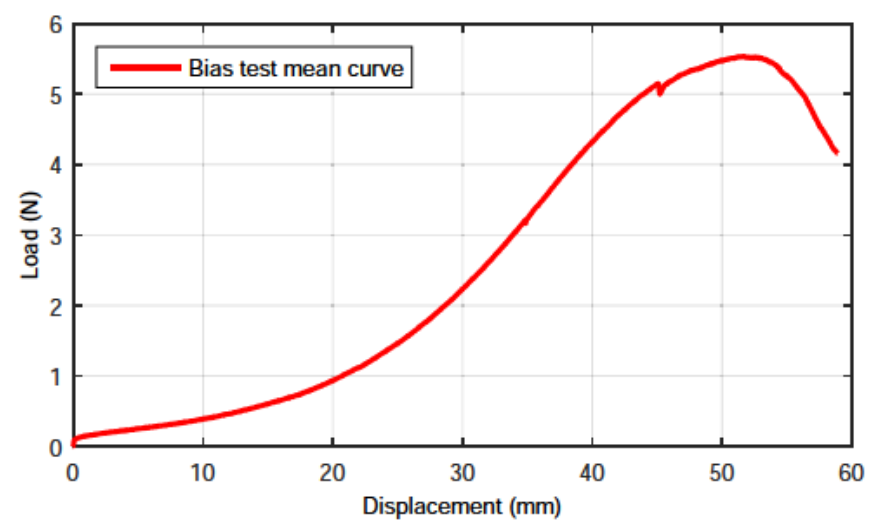

Fig. 5. Results of bias extension test of $48600 \mathrm{C} 1300$.

\subsubsection{Shear force during bias extension test}

The calculation of shear force measured in the uniaxial bias extension test per unit length, $F_{s h}$, can be predicted by the normalisation theory for the rate-independent fabric, using the relationships between the unit torque $C_{S}$ and the normalised shear force $F_{s h}$ :

$C_{S}(\gamma)=F_{s h}(\gamma) \cos (\gamma)$ and $C_{S}\left(\frac{\gamma}{2}\right)=F_{s h}\left(\frac{\gamma}{2}\right) \cos (\gamma)$

Based on recent reviews [45], the normalised shear force can be calculated as:

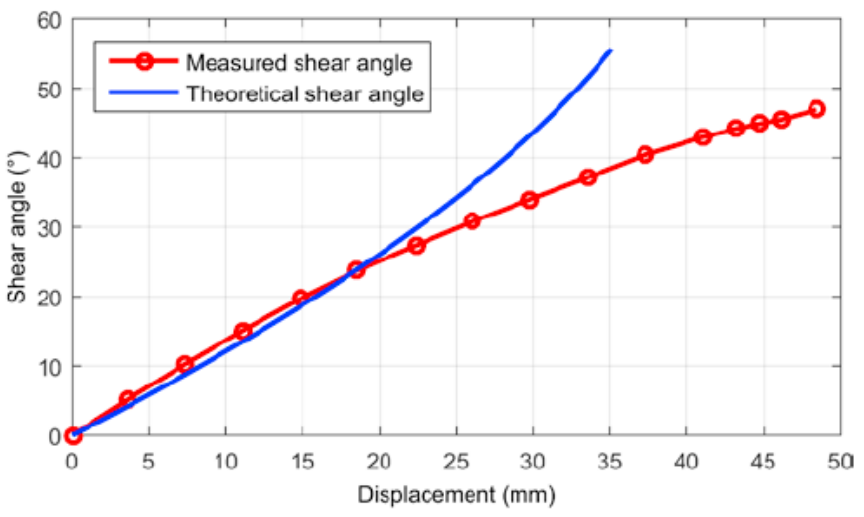

Fig. 6. Theoretical and measured shear angles for $48600 \mathrm{C} 1300$.

$$
\begin{aligned}
F_{s h}(\gamma)= & \frac{1}{(2 H-3 W) \cos (\gamma)}\left[\left(\frac{H}{W}-1\right) F\left(\cos \left(\frac{\gamma}{2}\right)-\sin \left(\frac{\gamma}{2}\right)\right)\right. \\
& \left.-W F_{s h}\left(\frac{\gamma}{2}\right) \cos \left(\frac{\gamma}{2}\right)\right] .
\end{aligned}
$$

Then, we assume that : $F_{\mathrm{sh}}(\gamma)=x[y-z]$ with

$x=\frac{1}{(2 H-3 W) \cos (\gamma)} ; y=\left(\frac{H}{W}-1\right) F\left(\cos \left(\frac{\gamma}{2}\right)-\sin \left(\frac{\gamma}{2}\right)\right) ;$

$z=W F_{s h}\left(\frac{\gamma}{2}\right) \cos \left(\frac{\gamma}{2}\right)$

We also assume that the function $F_{s h}$ can be approximated by a fifth degree polynomial:

$F_{s h}(\gamma)=a_{5} \gamma^{5}+a_{4} \gamma^{4}+a_{3} \gamma^{3}+a_{2} \gamma^{2}+a_{1} \gamma+a_{0}$

Hence, for five different values of $\gamma$, we can determined the coefficients of the polynomial, assuming $F_{s h}(0)=0$.

$$
\begin{aligned}
F_{s h}(\gamma)= & a_{5} \cdot \gamma^{5} \cdot\left(\frac{x z}{32}+1\right)+a_{4} \cdot \gamma^{4} \cdot\left(\frac{x z}{16}+1\right)+a_{3} \cdot \gamma^{3} \cdot\left(\frac{x z}{8}+1\right) \\
& +a_{2} \cdot \gamma^{2} \cdot\left(\frac{x z}{4}+1\right)+a_{1} \cdot \gamma \cdot\left(\frac{x z}{2}+1\right)
\end{aligned}
$$

For the woven $48600 \mathrm{C} 1300$, the normalised shear force is expressed as the following equation:

$F_{\text {sh }}(\gamma)=2.8450 \cdot \gamma^{5}-3.7092 \cdot \gamma^{4}+1.8682 \cdot \gamma^{3}-0.4168 \cdot \gamma^{2}+0.0514 \cdot \gamma$

Fig. 8 shows the non-linear curve shear force against the shear angle. It can be subdivided into three main phases. In the first stage, called placing, the shear load is relatively small (near $0 \mathrm{~N} \cdot \mathrm{mm}^{-1}$ ) and 

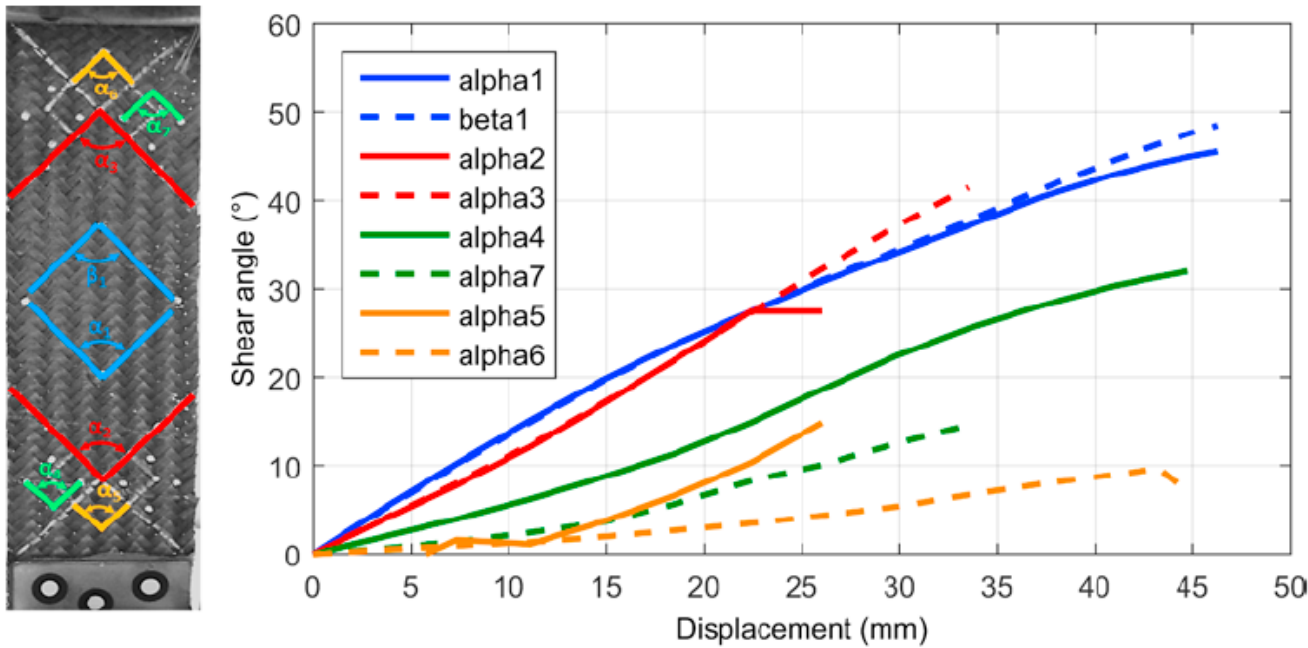

Fig. 7. Evolution of shear angle in pure shear zone, semi-sheared zones, and attachment zones during bias extension test.

increases linearly until $21^{\circ}$, with the fibre rotating and moving freely. In the second stage (transitional zone), the shear rigidity of the fabric and the external load increase sharply, and the fibre yarns begin to be in contact. In the third stage (locking), the limit of the shear angle is reached. Several woven characterisation studies indicate that the shear resistance increase significantly above the locking angle due to yarn compression [46,47]. In these tests, the average critical shear angle is $\gamma_{C} \approx 38^{\circ}$.

The shear modulus $\mathrm{G}_{12}$ is a characteristic variable. Understanding the shear modulus is paramount in any study on the shear behaviour of composite reinforcing fabrics. This modulus can be expressed as a function of the angle $(\gamma)$. Here, $(\gamma)$ is in radians. To identify this parameter, we used the trend curve of the normalised force $F_{\text {sh }}(\gamma)$. The shear stress is obtained by a direct division of the different values of the force normalised by the thickness of the woven fabric $\mathrm{e}=0.62 \mathrm{~mm}$. The shear stress $\tau(\gamma)$ comes out as

$\tau(\gamma)=4.588 \cdot \gamma^{5}-5.9826 \cdot \gamma^{4}+3.0133 \cdot \gamma^{3}-0.6723 \cdot \gamma^{2}+0.0829 \cdot \gamma$

Then, the shear modulus is calculated from the derivative of the regression equation determined from the data point on the shear stress versus the shear angle plot.

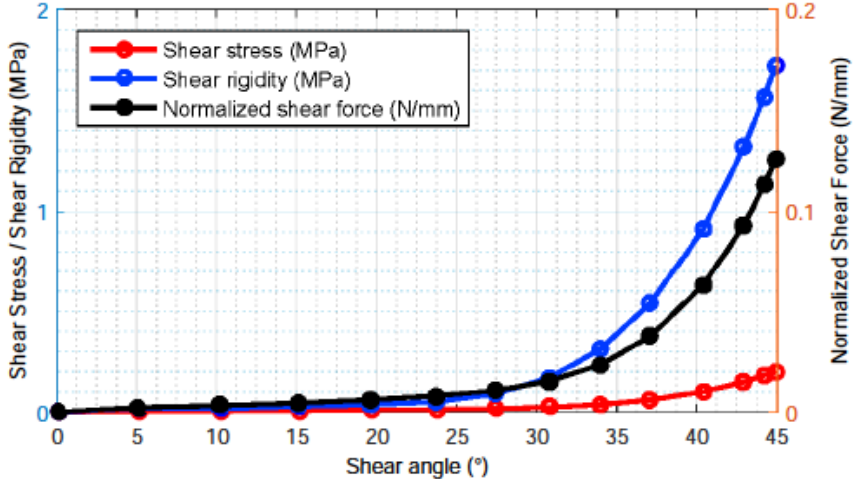

Fig. 9. Comparison of shear stress, shear rigidity, and normalised shear force.

$G_{12}(\gamma)=22.9438 \cdot \gamma^{4}-23.9304 \cdot \gamma^{3}+9.0399 \cdot \gamma^{2}-1.3447 \cdot \gamma+0.0829$

The procedure for shear modulus determination of the $48600 \mathrm{C}$ 1300 fabric starts by plotting the graph shown in Fig. 9. The shear angle

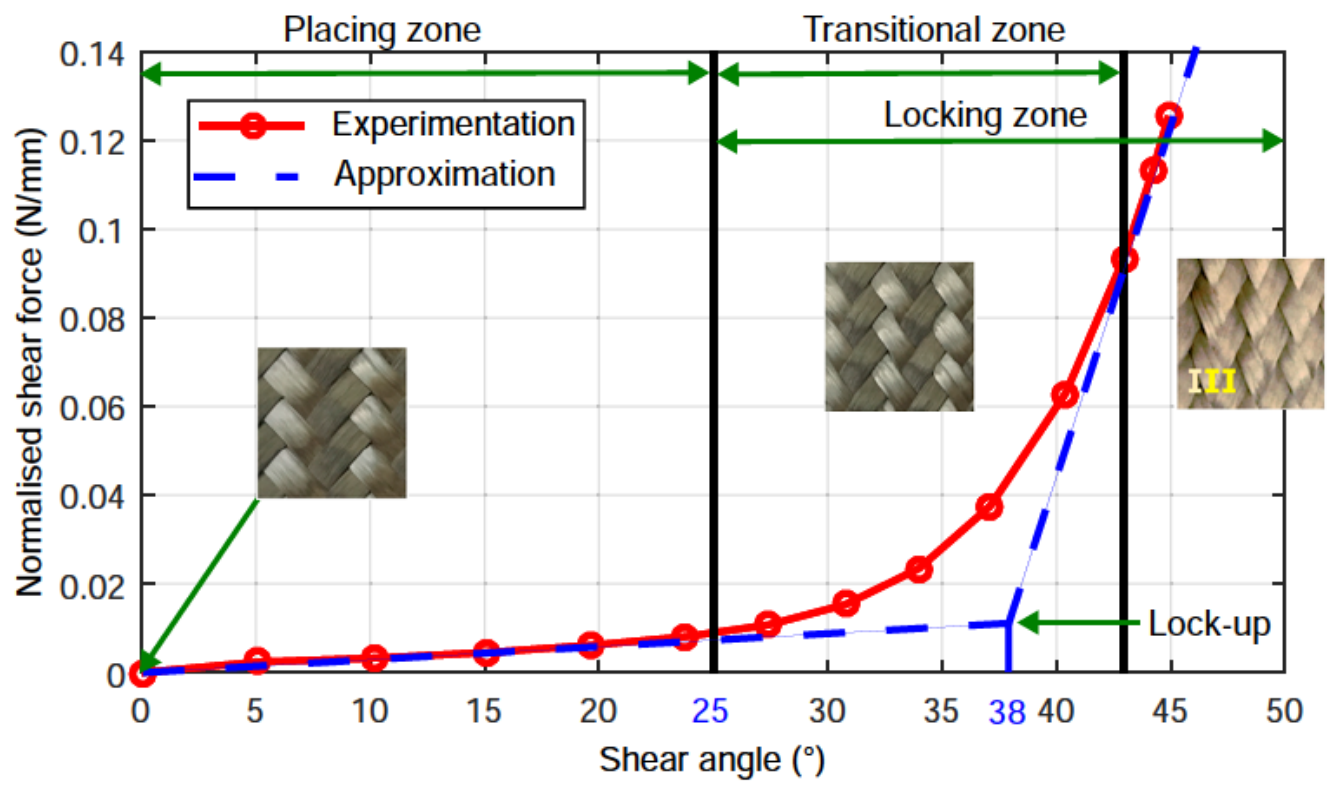

Fig. 8. Normalised shear force versus shear angle of woven fabric 48600 C 1300. 
is in radians and there are two vertical axes. The vertical axis on the left is in MPa and serves as a common scale for shear stress and shear rigidity. The right scale is for the normalised shear force with a unit of $\mathrm{N} /$ $\mathrm{mm}$. All three curves are drawn as a function of the shear angle in radians as an independent quantity. These results are the graphical representation of Eqs. (8) and (10).

3. Numerical modelling based on hybrid discrete hypoelastic model

\subsection{Principle of the approach used}

The hybrid discrete hypoelastic model of the fabric is built using a mesh of non-linear connectors and membrane elements (Fig. 10). The linear element represents the contribution of yarns in tension. The associated constitutive law is non-linear elastic with $\mathrm{K}(\mathrm{u})$, the connector stiffness, and automatically captures the evolution of the orientation of the principal load paths as the yarns rotate. The membrane/shell elements consider only the shear resistance of the fabric and have a zero tensile stiffness. The proposed model includes the following parameters: the element dimension $l_{0}$ and the stiffness of connectors $\left(\mathrm{F}_{\mathrm{c}}, \mathbf{u}_{\mathrm{c}}\right) . \mathrm{E}_{11}$, $E_{22}, G_{12}$, and e are respectively the in-plane stiffness, shear modulus, and the thickness of the hypoelastic continuous elements.

\subsection{Tension behaviour of non-linear connector elements}

The linear elements take into consideration the tensile contribution of the yarns of the fabric material behaviour and associated axial connectors, whose behaviour is non-linear $K(u)$. This approach consists of considering the beginning of the force-displacement curves identified experimentally in Section 2.4.

The non-linear stiffness associated with the connector level is calculated from the resulting behaviour based on the equivalent model of

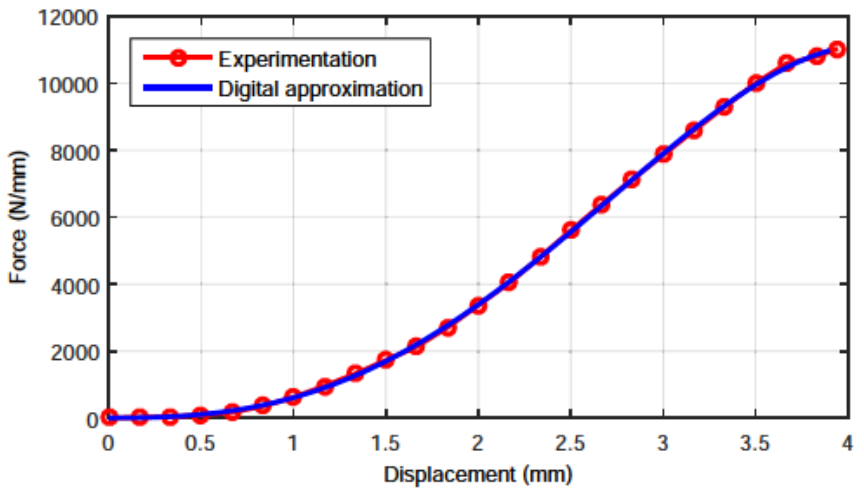

Fig. 11. Comparison of uniaxial tensile warp direction (experimental versus non-linear digital).

the test specimen $F_{t}$. The limits of the force and displacement of the connectors $\left(F_{c}, U_{c}\right)$ are defined from the following formulations:

$u_{c}=\frac{1}{N} u_{t}, F_{c}=\frac{1}{n+1} F_{t}, N=\frac{X}{l_{0}}$, and $n=\frac{Y}{l_{0}}$

Here, $\mathrm{X}$ and $\mathrm{Y}$ are respectively the length and width of the specimen. Simulated numerical tensile tests in the commercial software Abaqus/ Explicit are used. The tests are carried out on specimens of dimensions $150 \times 50 \mathrm{~mm}$ with an imposed displacement $\mathrm{U}=39 \mathrm{~mm}$, speed of $2 \mathrm{~mm} \cdot \mathrm{min}^{-1}$, and dimension of the mesh element $l_{0}=1 \mathrm{~mm}$. The number of connectors in the $\mathrm{Y}$ and $\mathrm{X}$ directions are respectively $N=150$ and $n=50$. To avoid extraction of the finite elements, the travel and load limits supported by the non-linear axial connectors are set as $\mathrm{Uc}_{\max }=0.026 \mathrm{~mm}$ and $\mathrm{Fc}_{\max }=215.47 \mathrm{~N}$. Fig. 11 shows a comparative result between the numerical and experimental responses. An examination of the tendency curve clearly shows the reproduction of

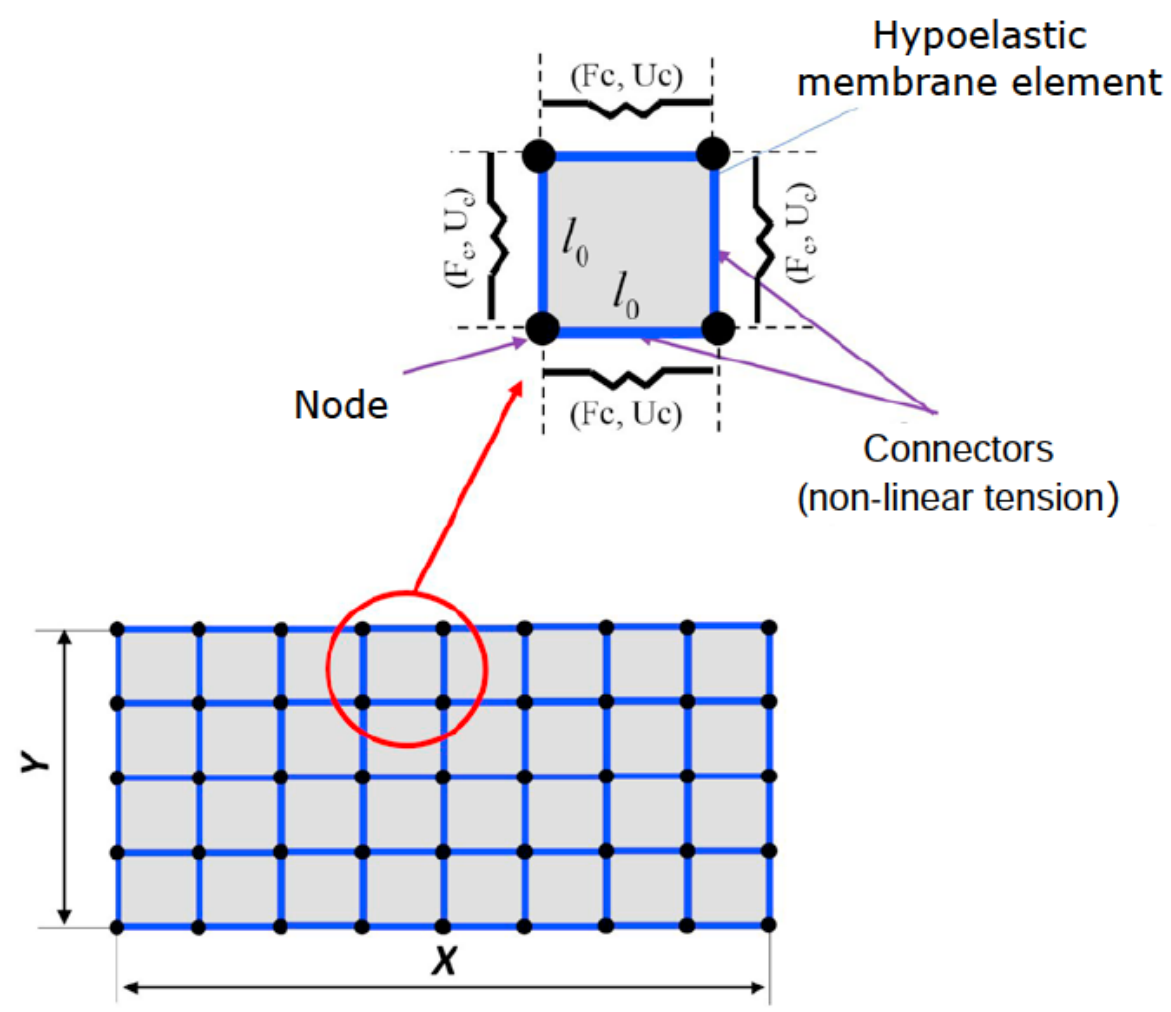

Fig. 10. Discretisation of the fabric. 
the digital approach by the experimental tensile behaviour.

\subsection{Shearing behaviour of continuous element}

The incorporation of the in-plane shear behaviour in a membrane element for the finite element is based on the hypoelastic model. The formulation of hypoelasticity is an objective derivative of the Cauchy stress tensor. It is a function of the current state of the stresses and the rate of deformation. It is commonly used for all non-linear behaviour types. It is necessary to define the form and guarantee the objectivity of the derivative quantities $\underline{\sigma}^{\nabla}$. The hypoelastic models are used while considering large deformations and non-linearities, both geometric and material $[18,48]$.

$\underline{\sigma}^{\nabla}=\underline{\underline{\underline{C}}}: \underline{D}$

Here, $\underline{D}$ and $\underline{C}$ are the strain tensor and Eulerian constitutive tensor Cauchy stress, respectively. $\underline{\sigma}^{\nabla}$ is also the objective derivative of $\underline{\sigma}$ defined to avoid stress change due to rigid body rotations in $\underline{\underline{\sigma}}=d \underline{g} / d t$.

$\underline{\underline{\sigma}}^{\nabla}=\underline{Q}\left(\frac{d}{d t}\left(\underline{Q}^{T} \underline{\underline{\sigma}} \underline{\underline{Q}}\right)\right) \underline{\underline{Q}}^{T}$

$Q$ is the rotation of the initial orthogonal frame to the so-called rotating frame where the objective derivative is made [9]. The objective derivative used is a rotational derivative of Green-Naghdi (GN). We remain in the general framework of an objective derived based on a rotation $\mathrm{R}$ with the associated basis $\left\{G N_{1,2}\right\}$. The principle is involved using the formula for updating the constraints, taking care to provide the projection tensor behaviour based on $\left\{G N_{1,2}\right\}$. For this, a manipulation is necessary because the latter is of known form only in the projection in $\left\{F_{1,2}\right\}$ [49]. This manipulation consists of a change in the behaviour matrix basis between the current fibre directions $\left\{F_{1,2}\right\}$ and the current orientations of GN axes. It is then necessary to determine the corresponding rotation tensor $\underline{\underline{R}}$, which is the tensor obtained from polar decomposition of the gradient such as

$\underline{\underline{R}}=\underline{\underline{F}} \underline{\underline{U}}^{-1}$

where $\mathrm{U}$ is the right stretch tensor. The $\mathrm{GN}$ basis, denoted as $G N_{1,2}$, is updated by the transportation of the initial basis, $G N_{1,2}^{0}$, by the rotation tensor $\underline{\underline{R}}$ :

$G \underline{N}_{1,2}^{0}=\underline{R} G \underline{N}_{1,2}^{0}$
The current fibre directions $F_{1,2}$, in the warp and weft directions are obtained from the deformation gradient tensor $\underline{\underline{F}}$ :

$\underline{F}_{1,2}=\frac{\underline{F} \cdot G N_{1,2}^{0}}{\left\|\underline{\underline{F}} \cdot G N_{1,2}^{0}\right\|}$

where $F_{1,2}^{0}$ and $G N_{1,2}^{0}$ are assumed to coincide initially (Fig. 12).

When both directions of fibre axes $F_{1,2}$ and $G N_{1,2}$ are determined, it is then possible to transform the strain increment from the current software working axes (GN) to yarn frame, because the two fibre axes directions $F_{1,2}$ do not remain orthogonal after deformation. Therefore, it is necessary to generate a new local orthogonal frame, where each of the two fibre axes will be defined [50]. Additionally, we construct two orthogonal frames, where each frame is based on one of the fibre axes. The first angle is $\theta_{1}$ between $G N_{1}$ and $F_{1}$. The second, $\theta_{2}$, is the angle between $\mathrm{GN}_{2}$ and $F_{2}$. These angles can be determined within the user subroutine via the deformation, which leads to the construction of two transformation matrices between this material basis and the GN one $[T]_{\left(G N_{1,2} ; F_{1,2}\right)}:$

$[T]_{\left(G N_{1,2} ; F_{1,2}\right)}=\left[\begin{array}{cc}\cos \theta_{1,2} & \sin \theta_{1,2} \\ -\sin \theta_{1,2} & \cos \theta_{1,2}\end{array}\right]$

The current fibre directions $F_{1,2}$ can be calculated from the initial fibre axes $F_{1,2}^{0}$ and from the deformation gradient such as

$\underline{F}_{1,2}=\frac{\underline{F} \underline{F}_{1,2}^{0}}{\left\|\overline{\bar{F}} \underline{F}_{1,2}^{0}\right\|}=\frac{\overline{\bar{F}} G N_{1,2}^{0}}{\left\|\overline{\bar{F}} G N_{1,2}^{0}\right\|}$

The increments of deformations are provided by Abaqus at the end of each loop, which makes it possible to calculate the deformation increments with respect to the two bases $\left(E_{1}, \frac{\underline{F}_{2}}{\left\|E_{2}\right\|}\right)$ and $\left(E_{2}, \frac{\underline{F}_{1}}{\left\|E_{1}\right\|}\right)$ using the principles of base change defined as

$[d \varepsilon]_{\left(F_{1}, F_{2}\right)}=\left[T_{1,2}\right]^{T}[d \varepsilon]^{G N}\left[T_{1,2}\right]$

where

$\left[T_{1}\right]=\left[\begin{array}{cc}T_{1}^{1} & T_{2}^{1} \\ T_{3}^{1} & T_{4}^{1}\end{array}\right]$ with $T_{1}^{1}=\cos \theta_{1} ; T_{2}^{1}=-\sin \theta_{1} ; T_{3}^{1}=\sin \theta_{1}$ and $T_{4}^{1}=\cos \theta_{1}$,

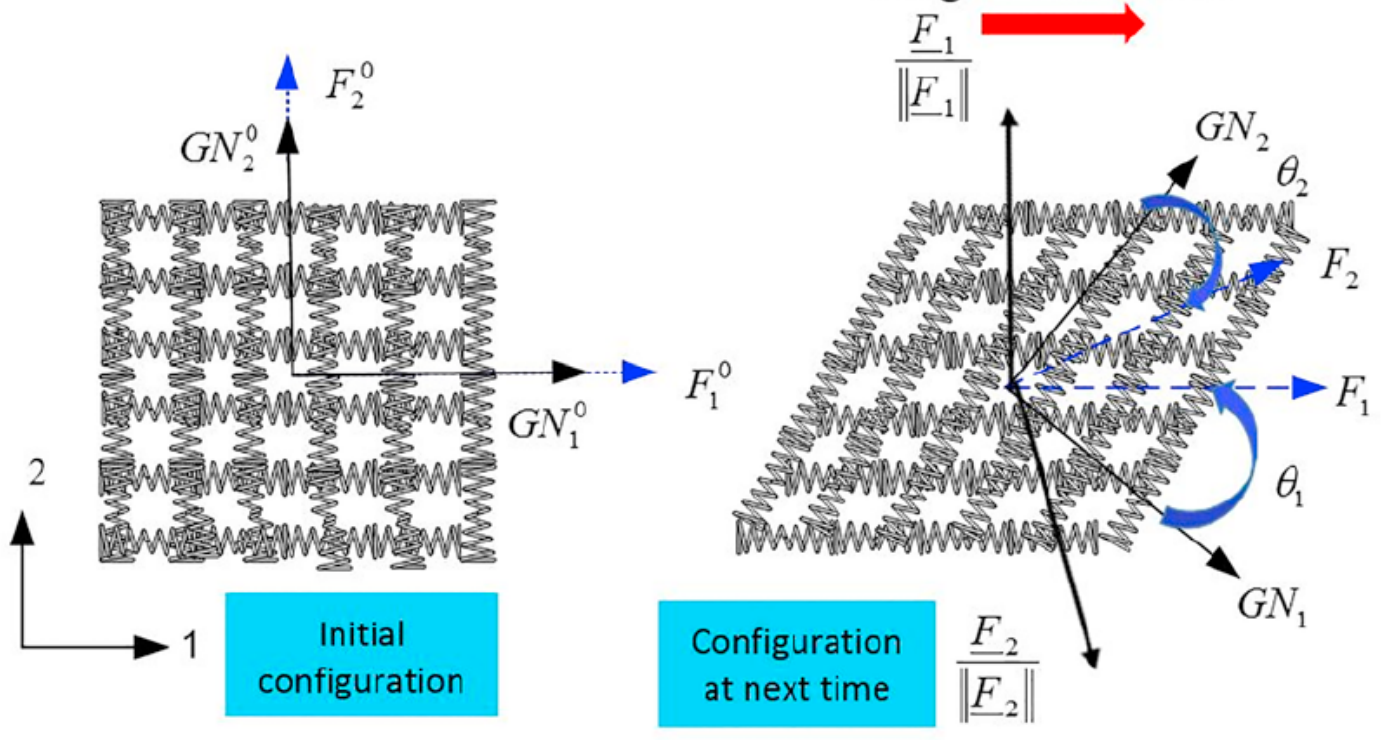

\section{Large deformation}


$\left[T_{2}\right]=\left[\begin{array}{cc}T_{1}^{2} & T_{2}^{2} \\ T_{3}^{2} & T_{4}^{2}\end{array}\right]$ with $T_{1}^{2}=\cos \theta_{2} ; T_{2}^{2}=-\sin \theta_{2} ; T_{3}^{2}=\sin \theta_{2}$ and $T_{4}^{2}=\cos \theta_{2}$

Then, the in-plane shear angle is defined as the change in the angle between the warp and weft yarns and specifically, here, it is defined by Eq. (2) in the bias test. Next, the constitutive law $[C]_{\left(F_{1}, F_{2}\right)}$, can be applied for each warp and weft fibre directions and solved for incremental stress in the fibre frames using

$[d \sigma]_{F_{1}}=[C]_{F_{1}}[d \varepsilon]_{F_{1}}$ and $[d \sigma]_{F_{2}}=[C]_{F_{2}}[d \varepsilon]_{F_{2}}$

where

$[C]_{F_{1}}=\left[\begin{array}{lll}E_{11} & 0 & 0 \\ 0 & 0 & 0 \\ 0 & 0 & G_{12}\end{array}\right]$ and $[C]_{F_{2}}=\left[\begin{array}{lll}0 & 0 & 0 \\ 0 & E_{22} & 0 \\ 0 & 0 & G_{12}\end{array}\right]$.

Here, $\left(E_{11}, E_{22}\right)$ and $G_{12}$ are the elastic tensile modulus and the inplane shear modulus. The hypoelastic model has been implemented in a VUMAT user subroutine in Abaqus/Explicit.

The increments of the constraints are then cumulated according to the classical formulation of Hughes and Winget [48]:

$\left(\sigma_{11}^{F_{1}}\right)^{n+1}=\left(\sigma_{11}^{F_{1}}\right)^{n}+\left(d \sigma_{11}^{F_{1}}\right)^{n+\frac{1}{2}}$

$\left(\sigma_{22}^{F_{2}}\right)^{n+1}=\left(\sigma_{22}^{F_{2}}\right)^{n}+\left(d \sigma_{22}^{F_{2}}\right)^{n+\frac{1}{2}}$

$\left(\sigma_{12}\right)^{n+1}=\left(\sigma_{12}\right)^{n}+\frac{1}{2}\left(d \sigma_{12}^{F_{1}}+d \sigma_{12}^{F_{2}}\right)^{n+\frac{1}{2}}$

Finally, the stresses in the two directions of the fibres are calculated and then projected into the GN base by the transformation

$\left(\sigma^{G N}\right)^{n+1}=\left[T_{1}\right][\sigma]_{G N}^{F 1}\left[T_{1}\right]^{T}+\left[T_{2}\right][\sigma]_{G N}^{F 2}\left[T_{2}\right]^{T}$

\subsection{Validation of continuous elements according to elementary tests}

For the validation of the hypoelastic model applied to continuous elements, we carried out a comparative study with the results of Khan [51] on a 3D quadrilateral membrane element with reduced integration (M3D4R). Three elementary tests were carried out on a single $1 \times 1 \mathrm{~mm}$ element with bidirectional fibres: (i) $45^{\circ}$ simple shear test, (ii) traction followed by $45^{\circ}$ simple shear, and (iii) traction followed by rigid body rotation [51].

For the three cases, the elongation is twice the length of the element $\left(\frac{l}{l_{0}}=2\right)$, the thickness of the membrane is $1 \mathrm{~mm}$, the tensile rigidity $\mathrm{E}_{\mathrm{i}}$ for both directions $(\mathrm{i}=1,2)$ is $34500 \mathrm{MPa}$, and there is no shear rigidity.

Strains after extension in the first direction $\left(\varepsilon_{1}\right)$, the final shear angle $\left(\gamma_{f}\right)$, and the final stresses are extracted from the numerical simulation (Table 2) and compared to Khan's results [51].

Three elementary tests were performed and found to have a good agreement with the literature. First, it is observed that the shear angle for tests 1 and 2 are $45^{\circ}$, whereas for test 3 , it is $0^{\circ}$. These results are consistent with the physical deformation of the fabric. For a simple shear test, the shear angle is $45^{\circ}$, and for a rigid rotation it is $0^{\circ}$. Therefore, the unit cell is well deformed for the shear test whereas for rigid rotation, it is not. Second, it is observed that for a simple tension test (tests 2 and 3 ) in the fibre direction, the strain output is 0.69 , which corresponds to the large strain theory. Third, it is observed that the stresses for simple shear computed for directions 1 and 2 are not equal to zero. Direction 2 is constrained (no displacement in direction 2 is allowed), which implies stresses in both directions. The values of the stresses are equivalent to Khan's value. For the tensile step (test 3), only the fibres in direction 1 are deformed. The stress in direction 1 is $2.45 \mathrm{E}+04 \mathrm{MPa}$, whereas in direction 2 it is $0 \mathrm{MPa}$.

Elementary tests allow the calculation of stresses, strains, and shear angles of a hypoelastic deformed fabric. The tension stresses obtained correspond exactly to the expected solutions in the case of a law linking the Cauchy constraints and the logarithmic deformations. This approach permits the calculation of the real characteristic, and the magnitudes of the output are equal to those in the literature. It describes well the behaviour in tension and there is no tension related to the rotation of rigid body. This approach is for rigid body rotations.

\subsection{Validation of the hybrid discrete method according to elementary tests}

In order to validate the hybrid discrete method, simple shear elementary test is carried out on a $1 \times 1 \mathrm{~mm}$ unit cell with a $1 \mathrm{~mm}$ thickness with 4 connectors. The difference with the validation of continuous element is that the membrane has no shear rigidity and has very low tensile rigidities: $\mathrm{E}_{1}$ and $\mathrm{E}_{2}$ are equal to 3.9 $\mathrm{MPa}$. The tensile rigidity is modelled by a linear connector stiffness equal to $12250 \mathrm{MPa}$.

The output results are presented in Table 3. The computed shear angle is equal to $45^{\circ}$ and the computed stresses are $2.45 \mathrm{E}+04 \mathrm{MPa}$ and $1.23 \mathrm{E}+04 \mathrm{MPa}$ for direction 1 and direction 2, respectively. By comparing with the previous elementary tests on a hypoelastic continuous cell only, both approaches provide the same result qualitatively and quantitatively, validating the hybrid discrete hypoelastic approach on an elementary application.

\subsection{Identification of the shear behaviour parameters}

The material parameters of the continuous elements are the Young modulus, thickness, and in-plane shear rigidity $\left(\mathrm{E}, \mathrm{e}\right.$, and $\mathrm{G}_{12}$ respectively). Our fabric is considered to be balanced $\left(E_{11}=E_{22}\right)$. Finite element analyses of the bias-extension test are performed within an optimisation loop in order to determine the characteristics of the membrane elements. The identification of the parameters is then carried out using the inverse method by comparing the force-displacement curve obtained from the maximum loading test. The maximum shear angle is determined by the angle between two connectors, each characterising a yarn direction. Two variants of this model have been tested. The first model is a hybrid hypoelastic behaviour of the shell with the in-plane shear rigidity $\mathrm{G}_{12}$ considered constant. The second one, with a non-linear shear modulus G, has been determined in Section 2.

The bias extension test parameters used for the numerical bias test are presented in Table 4.

Fig. 13 shows that the hypoelastic discrete hybrid model followed the woven fabric behaviour up to the displacement of $21 \mathrm{~mm}$, which corresponds to the beginning of the appearance of sliding in the bias tests. From this value, the two numerical and experimental curves diverge. Another numerical simulation of the bias extension test was carried out using the discrete hypoelastic hybrid model, where the shear modulus is not constant. This study made it possible to demonstrate the different shear zones according to the literature. A comparison between the experimental and numerical values (normalised load and shear angle) presented in Fig. 14 shows that they are in perfect agreement before the sliding begins and when reaching the locking

Table 2

Computed results for elementary tests on continuous element.

\begin{tabular}{|c|c|c|c|c|}
\hline Test no. & $\varepsilon_{1}$ & $\gamma_{\mathrm{f}}\left({ }^{\circ}\right)$ & $\begin{array}{l}\text { Computed stress tensor } \\
\sigma_{f}=\left\{\begin{array}{l}\sigma_{11} \\
\sigma_{22} \\
\sigma_{12}\end{array}\right\}_{M P a}\end{array}$ & $\begin{array}{l}\text { Khan's stress tensor [51] } \\
\sigma_{f K}=\left\{\begin{array}{l}\sigma_{11} \\
\sigma_{22} \\
\sigma_{12}\end{array}\right\}_{M P a}\end{array}$ \\
\hline 1 & - & 45 & $\sigma_{f}=\left\{\begin{array}{c}0 \\
1.23 E+04 \\
0\end{array}\right\}$ & $\sigma_{f K}=\left\{\begin{array}{c}0 \\
1.23 E+04 \\
0\end{array}\right\}$ \\
\hline 2 & 0.69 & 45 & $\sigma_{f}=\left\{\begin{array}{c}2.45 E+04 \\
1.23 E+04 \\
0\end{array}\right\}$ & $\sigma_{f K}=\left\{\begin{array}{c}2.45 E+04 \\
1.23 E+04 \\
0\end{array}\right\}$ \\
\hline 3 & 0.69 & 0 & $\sigma_{f}=\left\{\begin{array}{c}2.45 E+04 \\
0 \\
0\end{array}\right\}$ & $\sigma_{f K}=\left\{\begin{array}{c}2.45 E+04 \\
0 \\
0\end{array}\right\}$ \\
\hline
\end{tabular}


Table 3

Computed results for elementary tests on a single cell of the discrete hybrid method.

\begin{tabular}{lcc}
\hline Test no. & $\gamma_{\mathrm{f}}\left({ }^{\circ}\right)$ & Computed stress tensor \\
& $\sigma_{f}=\left\{\begin{array}{c}\sigma_{11} \\
\sigma_{22} \\
\sigma_{12}\end{array}\right\}_{M P a}$ \\
\hline 1 & 45 & $\sigma_{f}=\left\{\begin{array}{c}2.45 E+04 \\
1.23 E+04 \\
0\end{array}\right\}$ \\
\hline
\end{tabular}

Table 4

Numerical input for bias extension test.

\begin{tabular}{llll}
\hline $\begin{array}{l}\text { Element size } \\
\mathrm{L}_{0}(\mathrm{~mm})\end{array}$ & $\begin{array}{l}\text { Element } \\
\text { thickness } \\
\text { e (mm) }\end{array}$ & $\begin{array}{l}\text { Elastic modulus in both } \\
\text { directions } \\
\text { E1, E2 }(\mathrm{MPa})\end{array}$ & $\begin{array}{l}\text { In-plane shear } \\
\text { rigidity } \\
\text { G12 }(\mathrm{MPa})\end{array}$ \\
\hline 2.69 & 0.01 & 3.9 & 1.5 \\
\hline
\end{tabular}

angle. After this angle, the curves diverge because the numerical model does not consider the transverse compaction of the locks, which generates friction. A study on the sensitivity of the thickness to the normalised numerical values of shear forces and angles shows the independence of the results. Therefore, the actual value of the thickness of the fabric is equal to $0.62 \mathrm{~mm}$.

\section{Application of hemispherical composite forming}

To evaluate and show the potential of discrete hypoelastic approach with the VUMAT subroutine, a hemispherical forming was simulated in Abaqus/Explicit for comparison with the experimental results of hemispherical dome forming. The hybrid elements were automatically generated using Python scripts. The modelling case was created using three parts (the punch, blank holder, and die). The punch has a diameter of $50 \mathrm{~mm}$, and the die has a hole diameter of $55.4 \mathrm{~mm}$; hence, there is a gap of $2.7 \mathrm{~mm}$ between the punch and die. The curvature radius that links the vertical and horizontal surface of the die is $6 \mathrm{~mm}$ to prevent a severe curvature of the preform during forming. The total force applied on the holder is $238.45 \mathrm{~N}$. The fabric part represents the hybrid discrete elements and is the only deformable body in the simulation, with the punch, holder, and die parts represented by analytical rigid bodies.

For the balanced woven fabric of $4860013000 \mathrm{C}$ and to minimise the calculation time, the numerical symmetry is considered. The fabric is represented as a quarter model with $\mathrm{xy}$ and $\mathrm{yz}$ planes and the friction coefficient between the fabric and die is set as 0.2 , which is the average value used by Khan [51]. The contact condition is general (where all bodies are prevented from penetrating other bodies according to the 'general' contact rules in Abaqus).

The material characteristics and process parameters mostly used for numerical forming simulations are detailed in Table 5 .

Two different orientations were tested: the first one with the fibre orientated at $0^{\circ}$ and the second one at $45^{\circ}$.

\section{Results and discussions}

The woven fabric forming simulation was performed using the hybrid discrete hypoelastic approach presented above. The computed deformed shape was compared with the experimental shape in Fig. 15. The woven fabric was initially oriented at $0^{\circ} / 90^{\circ}$. After forming, the numerical simulation results and deformed fabrics were compared. A good correlation was observed between the results (Fig. 15a). The analysis is based on the position of borders of the sample. The contours of numerical and experimental deformed shapes are plotted in both $\mathrm{X}$ and $\mathrm{Y}$ directions as shown in Fig. 15b. It can be observed that the shapes of the contour of the experiments and numerical simulation are almost similar with a maximum gap in the $\mathrm{X}$ and $\mathrm{Y}$ directions of $8 \mathrm{~mm}$ and $10 \mathrm{~mm}$ respectively. This difference can be attributed to the difference between the real boundary conditions of the blank holder and the considered boundary conditions of the model. Moreover, in Fig. 15a, it was observed that on the free edges some fibres were slipping, making the post-treatment more difficult. The border profile corresponds when an assembly of the deformed numerical shape and experimental shape is performed. Both the model and experiment identified the same zone with high shear angles, as shown in Fig. 15.

Fig. 16 shows the deformed shape of the preformed fabric obtained from the forming simulation of a hemispherical model with a fibre orientation of $45^{\circ}$. The simulation results were compared with experimental values using real thickness and non-linear in-plane shear. In the same way as the preform oriented to $0^{\circ}$, the experiment and numerical results were assembled to compare the border shape and the shear angle. The shear angles were measured at 4 points (red points in Fig. 16a) with a marker tracking method of surface woven fabric. This measurement was only conducted on the flat face of the fabrics because there was only one camera (perpendicular to the initial preformed fabric) during the experiments. In the simulation, the shear angles were measured at the same position and the blank boundary was plotted, as shown in Fig. 16c. The gap between the simulated and experimental angles was less than $1^{\circ}$; therefore, the accuracy of the simulation is satisfactory.

This approach predicts the deformation of a two-dimensional fabric for $0^{\circ} / 90^{\circ}$ and $\pm 45^{\circ}$ fibre orientations with good accuracy. The numerical shear angles are equivalent to the experimental ones for both

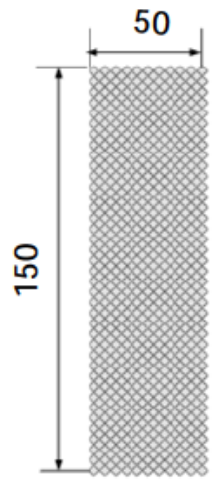

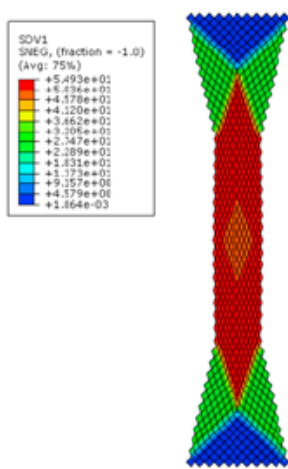

a)

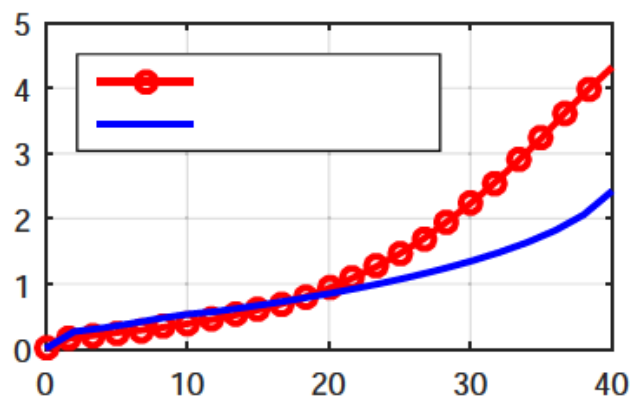

b)

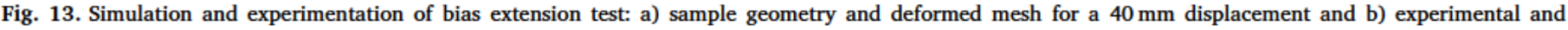
numerical load-displacement curves. 


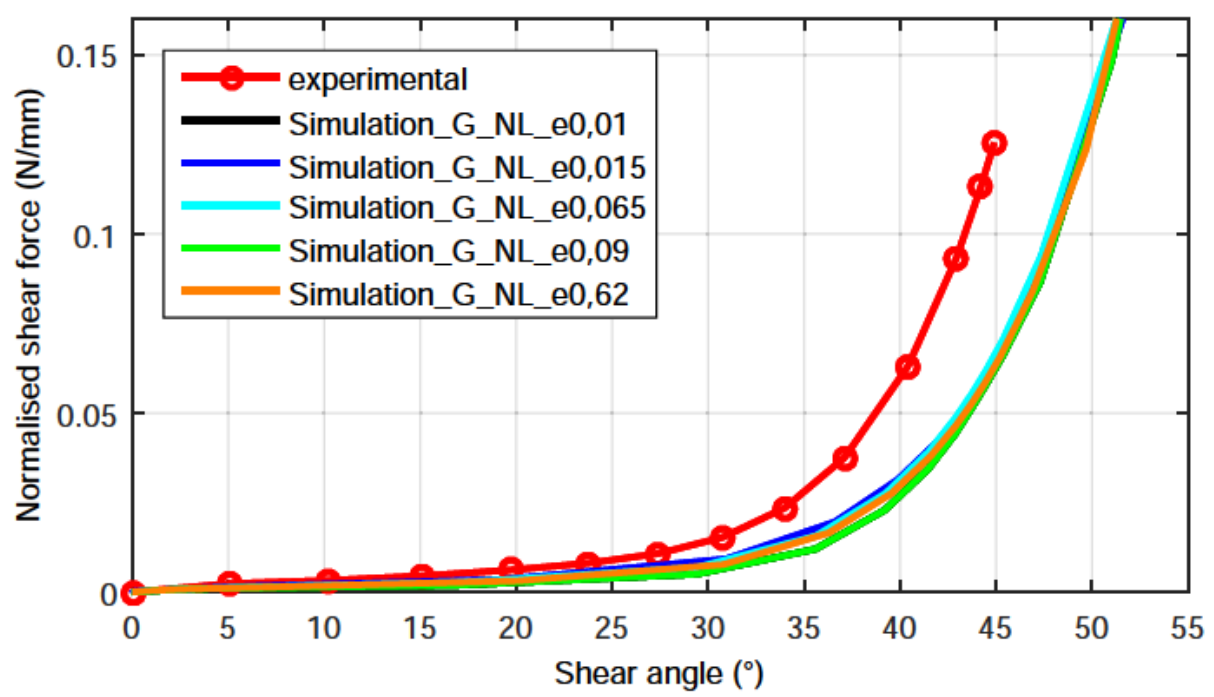

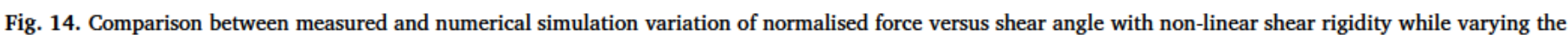
thickness.

Table 5

Numerical input for hemispherical forming.

\begin{tabular}{|c|c|c|c|c|}
\hline Element type & $\begin{array}{l}\text { Element size } \\
\mathrm{L}_{0}(\mathrm{~mm})\end{array}$ & $\begin{array}{l}\text { Element thickness } \\
\text { e (mm) }\end{array}$ & Elastic stiffness/rigidity & $\begin{array}{l}\text { In-plane shear rigidity } \\
\text { G12 (MPa) }\end{array}$ \\
\hline Connectors & 2.69 & - & K (Eq. (4)) & - \\
\hline Membrane & 2.69 & 0.62 & $\mathrm{E}_{1}=\mathrm{E}_{2}=3.9 \mathrm{MPa}$ & (Eq. (10)) \\
\hline
\end{tabular}

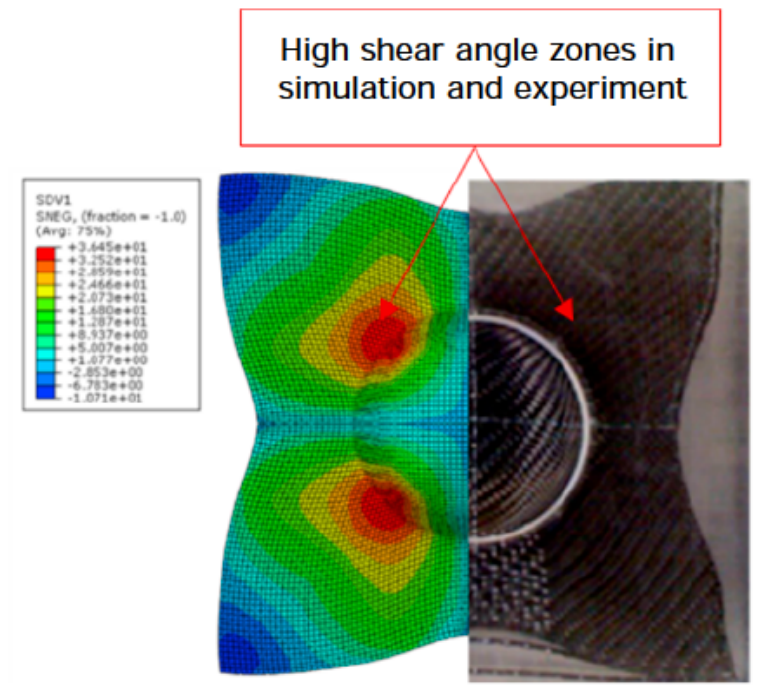

a) Numerical and experimental results

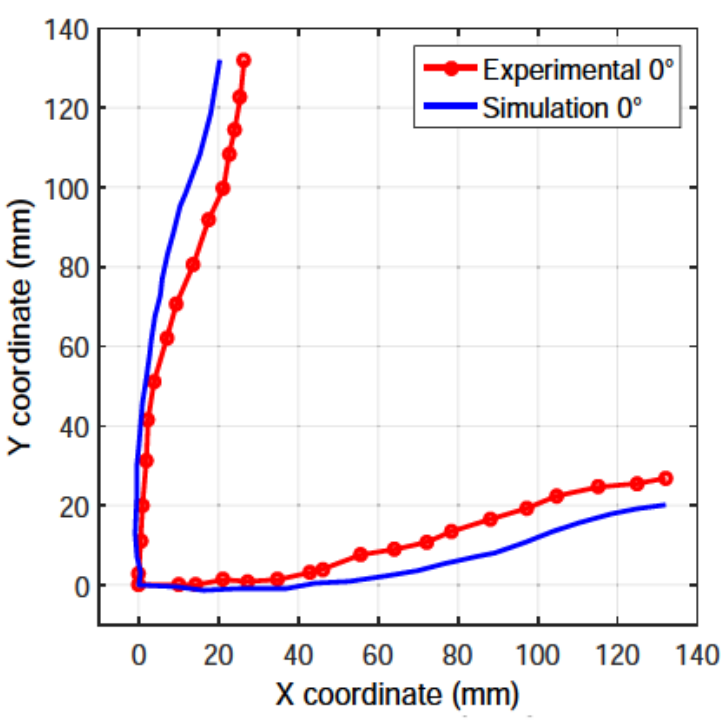

b) contour $\left(0^{\circ}\right)$

Fig. 15. Numerical and experimental results of dome forming with $0^{\circ} / 90^{\circ}$ initial orientations of tows: a) shear angle and b) contour.

orientations. Therefore, the algorithm using the hypoelastic law with an objective derivative describes well the rotation of fibres. Moreover, the shear behaviour, represented by a non-linear equation, is not sensitive to the real thickness, as shown in Fig. 14. Thus, the real behaviour can be input in the model instead of a numerical one in order to have a more realistic simulation. Furthermore, this approach shows a good behaviour for out-of-plane displacement as observed in the hemispheric forming. Because the connector and membrane element are both connected by nodes and both connectors and membrane edges will be strained in a straight way, both networks will be superimposed for every load. It has also been noted that when a shear load occurs, the non-linear rigidity of the connectors acts as a damper on the membrane element response. The non-linear hypoelastic hybrid approach is also able to predict stresses on the fibres, using the load inside the connectors, as demonstrated by Labanieh [52]. It also allows the determination of the stress tensor inside the continuous elements. These findings could be very useful for pre-impregnated materials because stresses due to the matrix could be computed and analysed. 

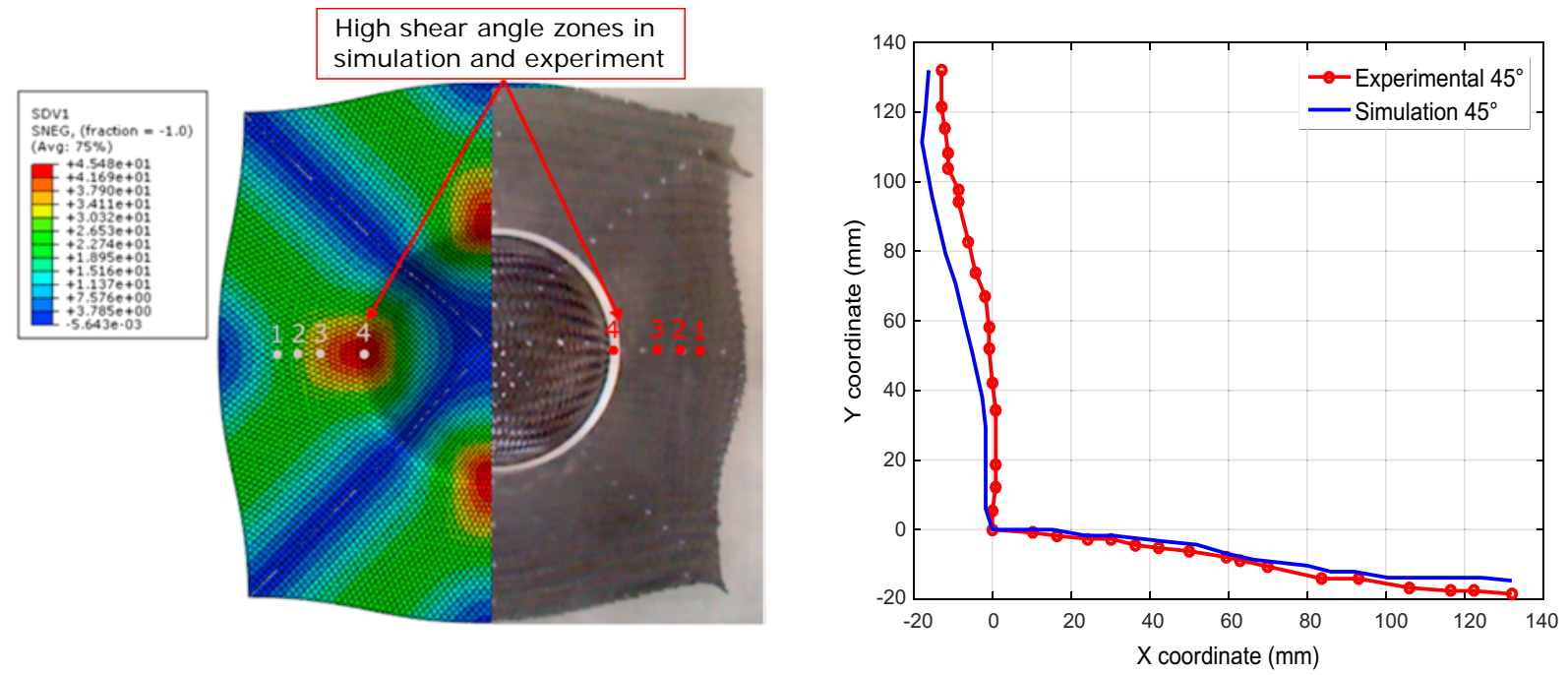

a) Numerical and experimental results

b) contour $\left(45^{\circ}\right)$

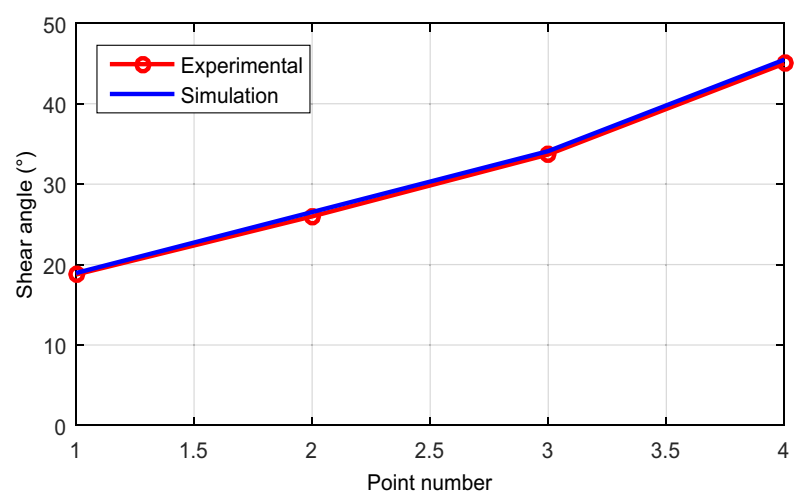

c) comparison between numerical and experimental shear angle

Fig. 16. Numerical and experimental results of dome forming with $45^{\circ} /-45^{\circ}$ initial orientations of tows: a) shear angle, b) contour, and c) comparison between experimental and numerical shear angle.

\section{Conclusions}

In this study, both experimental and numerical investigations were carried out. The methodology and the numerical model developed in this study allow the forming of dry woven fabrics. The main aim is to propose a simulation uncoupling the shear behaviour and tensile behaviour of the fabric. This simulation was developed via a linear connector element for the tensile behaviour and continuous membrane element for the shear behaviour. To obtain a more accurate model, a non-linear trend behaviour was used for tension and shear, and a hypoelastic behaviour was used to follow the rotation of the fibre during forming. With this discrete hypoelastic model, shear angles and locking angles are predicted and can be used for designing complex parts without generating defects.

First, the experimental study allows the characterisation of the fabric in tension and shear by using the mark tracking method during tensile tests and bias extension tests. Second, a methodology was developed to identify, from previous tests, the non-linear behaviour of the fabric. Two 4th order polynomial equations were identified to model the non-linear stiffness of the connector and the non-linear shear rigidity of the membrane element. Third, a highly accurate numerical model was developed to analyse the fabric deformation. This model involved the assembly of the non-linear tension behaviour of a linear connector element with the non-linear shear behaviour of a hypoelastic membrane element. This model was validated with some elementary tests found in the literature. A numerical model of the fabric forming process using a hemispherical punch was presented in the last section of this paper. It provided numerical results that were close to the experimental ones. Thus, the model was also validated in a more complex way.

The non-linear hypoelastic discrete model was developed for materials having two orthogonal directions of strong anisotropy. This model was able to predict fibre stresses and to determine, with high precision, the shear angles based on the modification of the orientation of the wires in large deformation. It was validated in different configurations, showing its ability to describe the composite behaviour and the high accuracy of shear angle prediction. Moreover, the proposed approach can be used to model the behaviour of pre-impregnated fabrics with unbalanced fabrics.

\section{Acknowledgements}

The authors acknowledged that this work relies jointly on the skills and material resources of these entities: UMSSTT-ENSIT, Tunisia and LGP at ENI de Tarbes, France for the experimental methods and numerical modelling. This work also benefits from the support of Nimitech Innovation Company.

\section{References}

[1] Abbassi F, et al. Experimental and numerical investigations of a thermoplastic composite (carbon/PPS) thermoforming. Struct Control Health Monit 2011;18(7):769-80.

[2] Ahmad F, et al. Numerical investigation to evaluate effect of fiber orientation on 
penetration-resistance of an aircraft composite material. Mech Adv Mater Struct 2018:1-9.

[3] Kim PJ, Lee DG. Surface quality and shrinkage of the composite bus housing panel manufactured by RTM. Compos Struct 2002;57(1):211-20.

[4] Han SH, et al. Study on high-speed RTM to reduce the impregnation time of carbon/ epoxy composites. Compos Struct 2015;119(Supplement C):50-8.

[5] Garnier C, Mistou S, Pantale O. Influence of process and material parameters on impact response in composite structure: methodology using design of experiments. Key Eng Mater 2010;446:83-90.

[6] Launay J, Duong AV, Hivet G, Valle V, Allaoui S. La mesure des déformations pour l'étude du comportement et la mise en forme des renforts de composites. 18ème Congrès Français de Mécanique. 2007. Grenoble.

[7] Soulat D, Allaoui S, Chatel S. Experimental device for the preforming step of the RTM process. Int J Mater Form 2009;2(1):181-4.

[8] Boisse P, Borr M, Buet K, Cherouat A. Finite element simulations of textile composite forming including the biaxial fabric behaviour. Compos B Eng 1997;28(4):453-64.

[9] Boisse P, Aimène Y, Dogui A, Dridi S, Gatouillat S, Hamila N, et al. Hypoelastic, hyperelastic, discrete and semi-discrete approaches for textile composite reinforcement forming. Int J Mater Form 2010;3(2):1229-40.

[10] Hamila N. Simulation de la mise en forme des renforts composites mono et multi plis. 2007.

[11] Van Der Weeën F. Algorithms for draping fabrics on doubly-curved surfaces. Int J Numer Meth Eng 1991;31(7):1415-26.

[12] Lim T-C, Ramakrishna S. Modelling of composite sheet forming: a review. Compos A: Appl Sci Manuf 2002;33(4):515-37.

[13] Hamila N, Boisse P. A meso-macro three node finite element for draping of textile composite preforms. Appl Compos Mater 2007;14(4):235-50.

[14] Vanclooster K, Lomov Stepan Vladimirovitch, Verpoest Et, Ignace VANCLOOSTER, Kristof LOMOV. Stepan Vladimirovitch, et VERPOEST, Ignace. Experimental validation of forming simulations of fabric reinforced polymers using an unsymmetrical mould configuration. Compos A Appl Sci Manuf 2009;40(4):530-9.

[15] Dong L, Lekakou C, Bader MG. Processing of composites: simulations of the draping of fabrics with updated material behaviour law. J Compos Mater 2001;35(2):138-63.

[16] Buet-Gautier K, Boisse P. Experimental analysis and modeling of biaxial mechanical behavior of woven composite reinforcements. Exp Mech 2001;41(3):260-9.

[17] Pu Xue XP, Cao Jian. A non-orthogonal constitutive model for characterizing woven composites. Compos A 2003;34:183-93.

[18] Bernstein B. Hypo-elasticity and elasticity. Arch Ration Mech Anal 1960;6(1):89-104.

[19] Hagège B, Boisse P, Billoët J-L. Finite element analyses of knitted composite reinforcement at large strain. Revue Européenne des Éléments Finis 2005;14(6-7):767-76.

[20] De Luycker E, et al. Simulation of 3D interlock composite preforming. Compos Struct 2009;88(4):615-23.

[21] Belytschko T, Liu WK, Moran B, Elkhodary K. Nonlinear Finite Elements for Continua and Structures. John Wiley \& Sons; 2013.

[22] Khan MA, et al. A parametric sensitivity study on preforming simulations of woven composites using a hypoelastic computational model. J Reinf Plast Compos 2015;35(3):243-57.

[23] Ten Thije RHW, Akkerman R, Huétink J. Large deformation simulation of anisotropic material using an updated Lagrangian finite element method. Comput Meth Appl Mech Eng 2007;196(33-34):3141-50.

[24] Aimène Y, et al. A hyperelastic approach for composite reinforcement large deformation analysis. J Compos Mater 2009;44(1):5-26.

[25] Erchiqui F, Gakwaya A. Analysis of long fibers direction of transversely isotropic hyperelastic material for thermoforming application. J Reinf Plast Compos 2005:24(9).

[26] Erol O, Powers BM, Keefe M. A macroscopic material model for woven fabrics based on mesoscopic sawtooth unit cell. Compos Struct 2017;180(Supplement C):531-41.

[27] Cavallaro PV, Johnson ME, Sadegh AM. Mechanics of plain-woven fabrics for inflated structures. Compos Struct 2003;61(4):375-93.

[28] Cherouat A, Billoët JL. Mechanical and numerical modelling of composite manufacturing processes deep-drawing and laying-up of thin pre-impregnated woven fabrics. J Mater Process Technol 2001;118(1):460-71.

[29] Cherouat A, Billoët JL. Finite element model for the simulation of preimpregnated woven fabric by deep-drawing and laying-up processes. J Adv Mater 2000;32(4):42-53.

[30] Sidhu RMJS, Averill RC, Riaz M, Pourboghrat F. Finite element analysis of textile composite preform stamping. Compos Struct 2001;52(3):483-97.

[31] Boubaker BB, Haussy Bernard, Ganghoffer Et, Jean-François. Discrete models of fabric accounting for yarn interactions: simulations of uniaxial and biaxial behaviour. Revue Européenne des Eléments 2005;14(6-7):653-75.

[32] Sharma SB, Sutcliffe MPF. A simplified finite element model for draping of woven material. Compos A Appl Sci Manuf 2004;35(6):637-43.

[33] Jauffrès D, Sherwood JA, Morris CD, Chen J. Discrete mesoscopic modeling for the simulation of woven-fabric reinforcement forming. Int J Mater Form 2010;3(2):1205-16.

[34] Najjar W, Legrand X, Cedric P, Soulat D, Boude S. A simple discrete method for the simulation of the preforming of woven fabric reinforcement. Key Eng Mater 2012 504-506: p. 213-218.

[35] Harrison P, Woong-Ryeol, et LONG YU, Andrew C. Rate dependent modelling of the forming behaviour of viscous textile composites. Compos A Appl Sci Manuf 2011;42(11):1719-2172.

[36] Wang P, Hamila N, Boisse P. Prédiction par simulation des défauts de plissement lors de la mise en forme des matériaux composites mono et multiplis. Matériaux \& Techniques 2012;100(6-7):591-9.

[37] Hexcel, Hexflow ${ }^{\circledast} 48600$ C 1300, in Fiche technique2015.

[38] Misnon MI, et al. Analyses of woven hemp fabric characteristics for composite reinforcement. Mater Des 2015;66:82-92.

[39] Gherissi A, et al. Numerical and experimental investigations on deep drawing of G1151 carbon fiber woven composites. Appl Compos Mater 2016;23(3):461-76.

[40] Erol O, Powers B, Keefe M. Development of a non-orthogonal macroscale material model for advanced woven fabrics based on mesoscale structure. Compos B Eng 2017; 110:497-510.

[41] Boisse P, Hamila N, Guzman-Maldonado E, Madeo A, Hivet G, Dell'Isola F. The biasextension test for the analysis of in-plane shear properties of textile composite reinforcements and prepregs: a review. Int J Mater Form 2017;10(4):473-92.

[42] Goidescu C, Welemane H, Garnier C, Fazzini M, Brault R, Péronnet E, et al. Damage investigation in CFRP composites usingfull-field measurement techniques: combination of digitalimage stereo-correlation, infrared thermography andX-ray tomography. Compos B Eng 2013;48:95-105.

[43] Harrison P, Clifford MJ, Long AC. Shear characterisation of viscous woven textile composites: a comparison between picture frame and bias extension experiments. Compos Sci Technol 2004;64(10):1453-65.

[44] Creech G, Pickett AK. Meso-modelling of non-crimp fabric composites for coupled drape and failure analysis. J Mater Sci 2006;41(20):6725-36.

[45] Cao J, Akkerman R, Boisse P, Chen J, Cheng HS, De Graaf EF, et al. Characterization of mechanical behavior of woven fabrics: experimental methods and benchmark results. Appl Sci Manuf Compos A 2008.

[46] Dumont, F., Expérimentations et modèles de comportement de renforts de composites tissés, 2003.

[47] Boisse P, Cherouat A, Gelin JC, Sabhi H. Experimental study and finite element simulation of a glass fiber fabric shaping process. Polym Compos 1995;16(1):83-95.

[48] Hughes TJ, Winget J. Finite rotation effects in numerical integration of rate constitutive equations arising in large-deformation analysis. Int J Numer Meth Eng 1980;15(12):1862-7.

[49] Hagege, Simulation du comportement mécanique des milieux fibreux en grandes transformations: application aux renforts tricotés, 2004.

[50] Saint-Marc JC, Gakwaya A. Development of a Ballistic Hybrid Fabric Model for Aeroengine fan Blade Containment Application. 2012.

[51] Khan MA, Numerical and experimental forming analyses of textile composite reinforcements based on a hypoelastic behaviour 2009-2010.

[52] Labanieh AR, Garnier C, Ouagne P, Dalverny O, Soulat D. Intra-ply yarn sliding defect in hemisphere preforming of a woven preform. Appl Sci Manuf Compos A 2018. 